\title{
Feasibility, Acceptability and Preliminary Efficacy of Dialectical Behavior Therapy for Autistic Adults without Intellectual Disability: A Mixed Methods Study
}

\author{
Doha Bemmouna ${ }^{1,4}$ (D) $\cdot$ Romain Coutelle $e^{1,3} \cdot$ Sébastien Weibel ${ }^{1,2} \cdot$ Luisa Weiner $^{2,4}$ \\ Accepted: 28 September 2021 / Published online: 9 October 2021 \\ (c) The Author(s), under exclusive licence to Springer Science+Business Media, LLC, part of Springer Nature 2021
}

\begin{abstract}
Self-harm and suicidal behaviors are prevalent among autistic adults without intellectual disability (ID). Emotion dysregulation (ED), the difficulty in modulating emotions, has been identified as an important risk factor. Dialectical behavior therapy (DBT) has been proved effective to treat ED in disorders other than autism spectrum disorder. Our study aimed at assessing the feasibility, acceptability and preliminary efficacy of DBT in seven autistic adults without ID exhibiting self-harm and/ or suicidal behaviors linked to severe ED. Our results suggest that DBT is feasible and highly acceptable to autistic adults without ID. Additionally, mean scores on the Difficulties in Emotion Regulation Scale decreased significantly post-treatment and at 4-month follow-up, suggesting that DBT might be efficacious in reducing ED in this population.
\end{abstract}

Keywords Autism spectrum disorder · Adults $\cdot$ Emotion dysregulation $\cdot$ Self-harm $\cdot$ Suicidality $\cdot$ Dialectical behavior therapy

Autistic adults are at greater risk of co-occurring psychiatric disorders, self-harm and suicidal behaviors compared to the general population (Hollocks et al., 2019; Licence et al., 2019; Cassidy et al., 2020; Moseley et al., 2020). A meta-analysis including 37 studies revealed a prevalence of self-harm of $42 \%$ in autistic individuals, irrespective of age and the presence or the absence of intellectual disability (ID) (Steenfeldt-Kristensen et al., 2020). In the first study investigating self-harming behaviors in autistic individuals without ID, Maddox et al. (2017) reported that 50\% of their sample had a history of self-harm, and that these behaviors were qualitatively similar to those seen in the general

Doha Bemmouna

dbemmouna@unistra.fr

1 Inserm U1114, 1 Place de l'Hôpital, 67000 Strasbourg, France

2 Psychiatry Department, University Hospital of Strasbourg, 1 Place de 1'Hôpital, 67000 Strasbourg, France

3 Expert Center of Autism Spectrum Disorder Without Intellectual Disability, 1 Place de l'Hôpital, 67000 Strasbourg, France

4 Present Address: Department of Psychology, University of Strasbourg, 12 Rue Goethe, 67000 Strasbourg, France population. Consistent with these findings, more recently, Licence et al. (2019) reported a prevalence of self-harm of $24 \%$ in their autistic sample. In addition to self-harm, suicidal ideation and suicidal attempts have also been reported at high rates in autistic individuals (Hedley \& Uljarević, 2018; Dell'Osso et al., 2019), with the prevalence of suicidal attempts ranging between 7 and 47\% (Zahid \& Upthegrove, 2017). Autistic adults without ID in particular appear to be at a greater risk for suicidal behaviors. Indeed, in a sample of recently diagnosed autistic adults without ID, $66 \%$ self-reported suicidal ideation and 35\% self-reported plans or attempts of suicide (Cassidy et al., 2014). More generally, two population-based cohort studies led in Denmark and Sweden highlighted the importance of this problem in autistic individuals, as they reported respectively a 3.7 and a 9-fold increase in death by suicide among autistic adults without ID compared to the general population (Hirvikoski et al., 2016; Kõlves et al., 2021).

Yet the increased risk of suicide in autism spectrum disorder (ASD) remains understudied. Recent research has highlighted several risk factors, including self-harming behaviors (Cassidy et al., 2018; Moseley et al., 2020), the severity of ASD symptoms (Cassidy et al., 2018; Costa et al., 2020), psychiatric comorbidities (Richa et al., 2014; Cassidy et al., 2018), loneliness and lack of social support 
(Hedley et al., 2017), camouflage of ASD characteristics (Cassidy et al., 2018) and, particularly, emotion dysregulation (ED) (Mazefsky et al., 2013; Moseley et al., 2019; Conner et al., 2020). ED is defined as the deficit in adaptive and efficient emotion regulation that interferes with appropriate goal-directed behavior (Gross, 1998). Several studies on clinical and non-clinical samples revealed a significant positive association between ED and self-harm (Wolff, 2019), as well as a significant positive association between ED and suicidal ideation and attempts (Turton et al., 2021). In ASD, ED has also been identified as a risk factor in the emergence of self-harm, as autistic individuals may use selfharming behaviors as a way to regulate painful emotions, i.e., low-energy affective states such as depression or highenergy affective states such as anger and anxiety (Moseley et al., 2019). Alexithymia, in particular, a prevalent trait in ASD (Kinnaird et al., 2019; Ziermans et al., 2019), has been identified as predictive of using self-harm to regulate emotions, especially those related to high-energy affective states (Moseley et al., 2019). In the context of alexithymia, selfharming behaviors are conceptualized as a way to communicate one's emotions when sharing them through words is not possible (Moseley et al., 2019). It has also been suggested that alexithymia interferes with emotion regulation, as it is difficult to regulate emotions that were not previously identified (Morie et al., 2019). In addition to self-harm, recent research has suggested an association between suicidal ideation and suicidal behaviors with ED in ASD. Indeed, in a sample of autistic children and adolescents, Conner et al. (2020) reported that greater ED was associated with an increased likelihood of suicidal ideation and attempts. More specifically, increased suicidality was found to be related to enhanced emotional reactivity and elevated dysphoria-i.e., low positive affect and motivation- in autistic individuals (Conner et al., 2020).

There is a growing body of literature suggesting that ED might be a relevant treatment target in autistic individuals (Reyes et al., 2019; Conner et al., 2020), especially those with self-harming behaviors and increased suicidality (Moseley et al., 2019; Conner et al., 2020). In autistic youth, preliminary evidence suggests that cognitive behavioral therapy (CBT) and mindfulness-based interventions might be effective for decreasing ED (e.g. Thomson et al., 2015; Weiss et al., 2018; Conner et al., 2019; Factor et al., 2019; Shaffer et al., 2019). However, to our knowledge, only two studies have focused on the treatment of ED in autistic adults. The first study (Conner \& White, 2018) evaluated the feasibility and the preliminary efficacy of a 6-week individual mindfulness intervention aiming to enhance emotion regulation abilities. The second study (Hartmann et al., 2019) assessed the effectiveness of a 12-week CBT- and DBT-informed group intervention aiming to enhance emotion regulation and social communication abilities. These studies have some limitations, however. First, the severity of the ED was not considered; second, individuals with severe comorbidities were excluded in the study by Conner and White (2018) and those with suicidal ideation were excluded in the study by Hartmann et al. (2019). Importantly, the intervention used in the study by Hartmann et al. (2019) mainly targeted social communication difficulties, hence the in-session practices focused exclusively on social situations. Findings on psychological treatments for ED associated with self-harm and suicidal behaviors in autistic adults without ID are therefore lacking.

Dialectical behavior therapy (DBT) (Linehan, 1993) has assembled a large body of evidence in the treatment of ED associated with self-harm and suicidal behaviors in borderline personality disorder (BPD) (Linehan et al., 2006; Panos et al., 2014). DBT is a third-wave CBT that combines acceptance-based techniques, including mindfulness training, and strategies from traditional CBT, including problemsolving, behavioral analysis, contingency management, and skills training techniques (Linehan, 1993). Comprehensive DBT relies on 4 primary modes: (a) weekly group skills training which covers 4 modules balancing acceptance-based skills (Mindfulness and distress tolerance) and change-oriented skills (Emotion regulation and interpersonal effectiveness); (b) weekly individual therapy; (c) as-needed intersession telephone contact between therapist and patient and (d) weekly consultation team meetings for DBT providers. Typically, DBT is provided over 12 months (Linehan, 1993). The optimal duration of DBT has been understudied, but some findings indicate that brief formats (e.g. 6-month, 16-week) are effective in treating ED (e.g. Koons et al., 2001; Stanley et al., 2007; Pasieczny \& Connor, 2011; Neacsiu et al., 2014; Delparte et al., 2019). Moreover, briefer formats have the advantage of being more feasible, cost-effective, and easily implementable in clinical settings (McMain et al., 2018).

In addition to BPD, DBT has been found to be effective in several psychiatric disorders characterized by ED, e.g., complex post-traumatic stress disorder (c-PTSD), depression, anxiety and eating disorders (Safer et al., 2001; Lynch et al., 2003; Chen et al., 2008; Harley et al., 2008; Bohus et al., 2013; Neacsiu et al., 2014). In addition, the efficacy of DBT has also been studied in adults with attention-deficit/ hyperactivity disorder (ADHD) (Hirvikoski et al., 2011; Philipsen et al., 2014; Fleming et al., 2015), suggesting its clinical pertinence in neurodevelopmental disorders.

In autistic individuals, DBT has been recommended to treat ED but its feasibility and preliminary efficacy have not been investigated (Hartmann et al., 2012; Mazefsky and White, 2014). Indeed, the preliminary study by Hartmann et al. (2019) is the only one that partially incorporated DBT skills and principles. Their results showed no significant improvement in emotion regulation among autistic participants, but they found a significant improvement in social 
communication, which was a major focus of their treatment. Thus, to date, there are no findings on the feasibility and/or the preliminary efficacy of an intervention based entirely on DBT in autistic adults without ID.

Given the high prevalence of ED, self-harm and suicidal behaviors in autistic adults without ID (Hirvikoski et al., 2016; Steenfeldt-Kristensen et al., 2020), the lack of evidence-based psychological treatments targeting severe ED in these adults (Bishop-Fitzpatrick et al., 2013; Shattuck et al., 2020), and the potential usefulness of DBT in ASD (Hartmann et al., 2012, 2019), it seems crucial to investigate the feasibility and utility of DBT in this population. This could foster research on the treatment of severe ED in autistic adults without ID and, more importantly, address their clinical needs (Murphy et al., 2016).

Our study aims to evaluate the feasibility, acceptability and preliminary efficacy of a brief 18-week DBT (Neacsiu et al., 2014; Weiner, 2019) for autistic adults without ID presenting with ED and self-harming and/or suicidal behaviors. In addition to being feasible and acceptable, we hypothesize that DBT will lead to a significant decrease in self-reported ED measured by the Difficulties in Emotion Regulation Scale (DERS; Gratz \& Roemer, 2004), as well as a significant improvement in self-reported depression, hopelessness, alexithymia, perceived quality of life and the frequency and intensity of self-harm and suicidal ideation.

\section{Methods}

\section{Participants}

Participants were recruited in the adult outpatient clinic of the Psychiatry Department of the University Hospital of Strasbourg. Among the ten participants initially approached, seven (three women and four men) were included and received at least half of the therapy, two were excluded and one declined to participate. The seven participants were aged between 19 and 56 years $(M=27.71 ; \mathrm{SD}=13.34)$. They had previous diagnoses of ASD supported by the Autism Diagnostic Interview-Revised (ADI-R; Rutter et al., 2003) and the Autism Diagnostic Observation Schedule, Second Edition revised module 4 (ADOS-2; Hus \& Lord, 2014; Lord et al., 2012), as well as previous IQ assessments based on the Wechsler Adult Intelligence Scale, Fourth Edition (WAIS-IV; Wechsler, 2011) indicating the absence of ID (Total IQ above 80). Total IQ scores ranged from 81 to 156 $(M=108.8 ; \mathrm{SD}=25.69)$ (Table 1).

In addition to a diagnosis of ASD without ID, adult participants had to meet the following two criteria to ensure that they fit the targeted severity: (a) having a DERS total score above the cut-off of 96 at baseline reflecting severe ED (Neaciu et al., 2014) and (b) exhibiting self-harming
Table 1 Sample description at baseline

\begin{tabular}{|c|c|}
\hline \multicolumn{2}{|l|}{ Demographics } \\
\hline Age, Mean (SD) & $27.71(13.34)$ \\
\hline Age range & $19-56$ \\
\hline \multicolumn{2}{|l|}{ Gender, n (\%) } \\
\hline Woman & $3(43 \%)$ \\
\hline Man & $4(57 \%)$ \\
\hline \multicolumn{2}{|l|}{ Ethnicity } \\
\hline European white & $7(100 \%)$ \\
\hline \multicolumn{2}{|l|}{ Marital status, n (\%) } \\
\hline Single & $6(86 \%)$ \\
\hline In relationship & $1(14 \%)$ \\
\hline \multicolumn{2}{|l|}{ Professional status, n (\%) } \\
\hline University student & $4(57 \%)$ \\
\hline Employed & $1(14 \%)$ \\
\hline Unemployed & $2(29 \%)$ \\
\hline \multicolumn{2}{|l|}{ Clinical variables } \\
\hline Total IQ mean (SD) & $108.8(25.69)$ \\
\hline IQ range & $81-156$ \\
\hline \multicolumn{2}{|l|}{ Other diagnoses, $\mathrm{n}(\%)$} \\
\hline ADHD & $2(29 \%)$ \\
\hline BPD & $1(14 \%)$ \\
\hline Current psychotropic medication, $\mathrm{n}(\%)$ & $5(71 \%)$ \\
\hline \multicolumn{2}{|c|}{ Psychological and psychiatric care prior to the study } \\
\hline $\mathrm{CBT}+$ psychiatric follow-up & $4(57 \%)$ \\
\hline Psychiatric follow-up only & $2(29 \%)$ \\
\hline No psychological or psychiatric care & $1(14 \%)$ \\
\hline Self-harming behaviors, $\mathrm{n}(\%)$ & $4(57 \%)$ \\
\hline Suicidal ideation, n (\%) & $5(71 \%)$ \\
\hline History of suicide attempts, n (\%) & $5(71 \%)$ \\
\hline
\end{tabular}

and/or suicidal behaviors, including suicidal ideation, in the last year prior to the study (Table 2). DERS total scores at inclusion ranged from 107 to $144(M=123.57$; $\mathrm{SD}=13.56)$.

Two participants were excluded respectively due to frequent hospitalizations related to a comorbid bipolar disorder and failing to complete post-treatment measures. One participant joined the group in the second half of therapy and followed the first part later in an individual setting.

Medication was unchanged during the study.

Participants received no financial incentives. Their participation was motivated by the potential benefits of the therapy on their mental health.

\section{DBT Intervention}

The intervention was based on the 4 components of comprehensive DBT (Linehan, 1993), i.e., (a) a 2 h15 weekly skills training group session (Neacsiu et al., 2014; Weiner, 2019) (Table 3), (b) a weekly 1-h individual therapy session, (c) 
Table 2 Self-harming behaviors, suicidal ideation and suicide attempts in participants

\begin{tabular}{|c|c|c|c|c|c|c|c|}
\hline Participants & Self-harm & Nature of self-harm & $\begin{array}{l}\text { Occurrence of self- } \\
\text { harming behaviors } \\
\text { before therapy }\end{array}$ & $\begin{array}{l}\text { Suicidal } \\
\text { ideation }\end{array}$ & $\begin{array}{l}\text { Occurrence of suicidal } \\
\text { ideation before therapy }\end{array}$ & $\begin{array}{l}\text { Number of } \\
\text { previous suicide } \\
\text { attempts }\end{array}$ & $\begin{array}{l}\text { Baseline } \\
\text { DERS total } \\
\text { score }\end{array}$ \\
\hline 1 & - & - & - & Yes & Very frequent* & 1 & 107 \\
\hline 2 & Yes & Self-punching & $\begin{array}{l}\text { On average } 1 \text { occur- } \\
\text { rence/month }\end{array}$ & - & - & - & 123 \\
\hline 3 & Yes & $\begin{array}{l}\text { Scratching, punching } \\
\text { things }\end{array}$ & $\begin{array}{l}\text { On average } 1 \text { occur- } \\
\text { rence/month }\end{array}$ & Yes & Frequent $* *$ & 2 & 126 \\
\hline 4 & Yes & $\begin{array}{l}\text { Inserting needles into } \\
\text { the body, genital } \\
\text { mutilation }\end{array}$ & $\begin{array}{l}\text { On average } 2 \text { occur- } \\
\text { rences/month }\end{array}$ & Yes & Frequent $* *$ & - & 107 \\
\hline 5 & - & - & - & Yes & Occasional & 3 & 106 \\
\hline 6 & - & - & - & Yes & Very frequent* & 1 & 144 \\
\hline 7 & Yes & Skin cutting & $\begin{array}{l}\text { At least } 3 \text { occurrences/ } \\
\text { week }\end{array}$ & Yes & Very frequent* & 4 & 135 \\
\hline
\end{tabular}

* Several times a week

**Several times a month

Table 3 DBT skills training program

\begin{tabular}{lll}
\hline Modules & \multicolumn{2}{l}{ Skills } \\
\hline Mindfulness & 1 & $\begin{array}{l}\text { Wise Mind and the « What» skills } \\
\text { of mindfulness }\end{array}$ \\
& 2 & The « How» skills of mindfulness \\
Distress tolerance & 3 & STOP and TIPP skills \\
& 4 & ACCEPTS skills \\
& 5 & IMPROVE and self-soothing skills \\
& 6 & Radical acceptance and willingness \\
Interpersonal effectiveness & 7 & DEAR MAN skills \\
& 8 & GIVE and FAST skills \\
& 9 & Validating others and self-validation \\
Debriefing session & & \\
Mindfulness & 10 & Mindfulness skills review \\
Emotion regulation & 11 & Identifying and labeling emotions \\
& 12 & Checking the facts \\
& 13 & Opposite action \\
& 14 & Problem solving \\
& 15 & ABC skills \\
Debriefing session & 16 & PLEASE skills \\
& & \\
\hline
\end{tabular}

access to telephone coaching and, (d) a weekly 2-h therapist consultation.

The 18-week brief DBT protocol applied is based on Neacsiu et al. (2014) and Weiner (2019). The program included 16 skills training sessions and 2 debriefing sessions at mid- and end-of-therapy. The four modules of DBT skills (mindfulness, emotion regulation, distress tolerance and interpersonal effectiveness) were covered during the 16 skills training sessions. The 16-week program developed by Neacsiu et al. (2014) does not include the debriefing sessions. These debriefing sessions were an opportunity to review the skills learned in the previous sessions, to roleplay or model skills, to answer questions and provide additional explanations of the skills if needed, and to collect feedback from participants on their experience in the group sessions, as well as their recommendations (Weiner, 2019). The duration of the intervention is consistent with the length of CBT programs targeting affective disorders in autistic individuals (number of sessions ranging from 4 to 50 and the duration of sessions ranging from 40 to $180 \mathrm{~min}$ ) (Weston et al., 2016). Moreover, based on previous studies recommending to extend CBT treatments when provided to autistic individuals (e.g. Maddox et al., 2019), the two debriefing sessions added to the 16-week DBT program (Neacsiu et al., 2014) allowed us to meet this recommendation in order to enhance skills learning. In addition, our program consisted of the four modes of DBT - i.e., weekly skills training, weekly individual therapy, telephone coaching and consultation team (Linehan, 1993) - whereas Neacsiu et al.'s (2014) consisted of group skills learning only.

DBT was initially scheduled for January 2020 to late May 2020. However, due to the COVID-19 pandemic, group sessions were interrupted mid-therapy (between March 2020 and June 2020), and the intervention ended in early August 2020. During the two-month interruption, individual sessions continued via phone, video calls or email for those who were not comfortable with phone or video-calls. In addition, every week, participants received a 10 to a 20 -min video made by our DBT team reviewing skills previously seen in group sessions.

Adaptations were introduced to DBT to adjust the therapy to the needs of autistic adults without ID (Attwood, 2003; 
Anderson \& Morris, 2006). Firstly, because of the cognitive inflexibility found in autistic individuals (Nyrenius \& Billstedt, 2020), the therapy environment was kept as stable as possible (room, room layout, schedule, facilitators, etc.) and individual sessions were ritualized on a regular schedule for the majority of the participants. Secondly, given the sensory particularities of the participants, we administered the Adolescent/Adult Sensory Profile pre-treatment (A/ASP; Brown \& Dunn, 2002). Because the majority of participants had auditory hypersensitivity, the skills training took place in the quietest room of the clinic to avoid noise disturbance. The room was also equipped with two air conditioners to adjust the temperature if necessary. Thirdly, as social anxiety is common in autistic individuals (Maddox \& White, 2015), we addressed this issue in three ways: (a) the individual barriers to participating in the skills-training group (e.g. the anxiety of being in the presence of other people, the fear of dealing with social interactions in the group, the fear of speaking up in the group) were identified and addressed through psychoeducation and/or problem-solving during the pre-treatment phase, (b) participants were given the possibility to be accompanied to join the group therapy room from the waiting room if needed, and (c) an activity was proposed in the first session to normalize emotions related to anxiety. The activity consisted of anonymously revealing one's anxiety level on a scale of 1 to 4 on a piece of paper and putting it in a ballot box. Then a facilitator counted out loud the papers allowing the participants to realize that anxiety was a shared experience in the group. Fourthly, due to information processing abnormalities found in autistic individuals (e.g. slower information processing, difficulty in selecting relevant information due to weak central coherence, deficits in conceptual reasoning) (Williams et al., 2015; Haigh et al., 2018), DBT patient manuals were modified through a significant reduction in text and the addition of models and images illustrating the skills. We also incorporated the "emotional thermometer", i.e., a visual tool widely used in ASD to help identify the intensity of emotions (Attwood, 2003). In addition, the facilitators gave concise instructions and explanations based on the use of concrete examples, role-playing and modeling. The mindfulness practices proposed at the beginning of skills training sessions were also based on precise and clear instructions, inviting participants to focus their attention on concrete elements of the present moment (e.g. breath, body sensations, environment sounds, objects) (Spek et al., 2013; Kiep et al., 2015). Fifthly, due to planning difficulties related to executive dysfunction (Wallace et al., 2016), support for planning between-sessions practices was provided when needed. Finally, given that autistic individuals are highly motivated to engage in their focused interests and are more motivated than non-autistic individuals by intrinsic motivational factors (Grove et al., 2016), participants' focused interests were used in examples during group sessions and incorporated when possible to in between-session practices to enhance their motivation.

\section{Therapists}

The skills training group and individual therapy were provided by a senior clinical psychologist (LW, professor of clinical psychology) and a graduate-level clinical psychology intern (DB). LW is a CBT and DBT specialist (trainings attended include DBT foundational training, DBT advanced training, DBT for leaders, DBT for PTSD provided by certified trainers and clinicians-e.g., Shelley McMain, Michaela Swales). DB was trained in DBT during her master's program, which includes a full module on DBT provided by LW, as well as a one-year clinical experience in the DBT clinic of the University Hospital of Strasbourg. The senior psychologist provided weekly supervision to the intern. The therapists relied on the French version of the DBT Skills Training Manual (Linehan, 2017) and participated in weekly team consultations to discuss complex cases and increase adherence to the DBT model.

\section{Measures}

\section{Feasibility and Acceptability}

Feasibility and acceptability were assessed via (a) the attrition rate, i.e., the percentage of dropouts from therapy, (b) the attendance rate, i.e., the overall percentage of attendance at group sessions, and (c) satisfaction measured quantitatively post-treatment using the Client Satisfaction Questionnaire for psychotherapeutic services (CSQ-8; Sabourin et al., 1989), an 8-item questionnaire using a 4-point Likert scale ( $1=$ not at all satisfied, $4=$ completely satisfied $)$ that assesses overall satisfaction with psychotherapeutic care received in inpatient or outpatient services. The measure has excellent psychometric properties when assessing psychotherapy outcomes (Attkisson \& Zwick, 1982; Sabourin et al., 1989). Satisfaction was also measured qualitatively through the investigation of participants' subjective experiences of DBT using a semi-structured interview conducted post-treatment by one of the therapists (DB). Despite the potential biases associated with this procedure (e.g., social desirability, lack of neutrality of the interviewer; Collins et al., 2005), this method was preferred for three reasons. First, we aimed at fostering feasibility by reducing the social anxiety and the change anxiety of the participants. Indeed, minimizing potential distress levels is a concern while conducting qualitative research in autistic individuals (e.g. recruiting through a person close to the individual, giving as much detail as possible about the process in advance) (Robertson and Simmons, 2015; Camm-Crosbie et al., 2019). Second, there were no personal relationships between any of the therapists and 
any of the participants, maximizing both the therapist and participants' neutrality in the context of the study. Third, the two therapists analyzed the data. Given the absence of qualitative findings on the effects of DBT on autistic individuals, the data were analyzed from an exploratory perspective. Therefore, it was useful to have a background on the subjective experiences to minimize the risk of fragmenting and decontextualizing them in the coding process. The interview template utilized open-ended questions designed to explore participants' experiences in 3 broad areas: (i) experience of the group therapy (e.g. how did you feel in the group during the group sessions?), (ii) experience of the individual therapy (e.g. What did you think of the individual sessions? How useful were they for you?) and (iii) overall impact of the therapy on their lives (e.g. To what extent, if any, has the therapy impacted your daily life?). At the beginning of each interview, the interviewer made it clear to participants that she was interested in learning about their subjective experience, and that there were no right or wrong answers and no obligation to answer any question.

\section{Preliminary Efficacy}

To evaluate preliminary efficacy, we administered the following self-report scales pre-treatment (January 2019), posttreatment (June 2019 for the two who participated in half of the therapy and August 2019 for the ones who completed the therapy) and at a 4-month follow-up.

Difficulties in Emotion Regulation Scale (DERS; Gratz \& Roemer, 2004), in its French version (Dan-Glauser \& Scherer, 2013), is our primary efficacy outcome. DERS measures difficulties in regulating emotions. It consists of 36 items grouped into 6 dimensions: (a) non-acceptance of emotional responses ("Non-acceptance"), (b) difficulty engaging in goal-directed behavior when distressed ("Goals"), (c) impulse control difficulties when distressed ("Impulse"), (d) lack of awareness of emotions ("Awareness"), (e) limited access to strategies for regulation ("Strategies") and (f) lack of emotional clarity ("Clarity"). Items are rated on a 5 -point Likert scale ( $1=$ almost never, $5=$ almost always). Higher scores correspond to greater difficulties. The DERS has adequate internal consistency (Cronbach's $\alpha=0.93$ ), test-retest reliability $(r=0.88)$, and construct and predictive validity among a college sample (Gratz \& Roemer, 2004). McVey et al. (2021) provided preliminary evidence for the utility of the DERS in autistic adolescents and adults. Their results supported a 6-factor structure, similar to that found in the general population (Gratz \& Roemer, 2004). However, minor differences were identified: items 1 and 7 loaded onto Awareness instead of Clarity, items 22 and 24 loaded onto Awareness instead of, respectively, Strategies and Impulse and item 34 did not load onto any factor. In the autistic sample, the DERS subscales showed good internal consistency (Cronbach's $\alpha$ values ranging from 0.80 to 0.90). The tool also showed good construct validity as 5 of the DERS subscales were positively correlated to the Beck Anxiety Inventory (BAI; Beck et al., 1988) and the Beck Depression Inventory-Second Edition (BDI-II; Beck et al., 1996). In the current study, the DERS total and subscale scores were calculated considering the minor modifications supported by these findings. In the absence of an official cut-off, we used the one by Neacsiu et al. (2014) to set the score of 97 as the threshold for severe ED. The internal consistency of the DERS for baseline total scores in the current sample was good $(\alpha=0.78)$.

Beck Depression Inventory-Second Edition (BDI-II; Beck et al., 1996), French validation by Bourque and Beaudette (1982), is a 21-item questionnaire that assesses the severity of depression. Items are rated on a scale from 0 to 3 $(0=$ least, $3=$ most $)$. Meta-analysis on 144 studies showed that the BDI-II has strong psychometric properties (Erford et al., 2016). In autistic adults, the BDI-II has strong reliability and validity, as well as a moderate ability to discriminate between depressed and non-depressed individuals (Williams et al., 2021). We calculated BDI-II autism-specific T-scores as suggested by Williams et al. (2021). A person with a $\mathrm{T}$-score $\leq 49.1$ is considered as unlikely depressed, with a T-score $>49.1$ as possibly depressed, with a T-score $>50.4$ as likely depressed, with T-score $>56.7$ as very likely depressed, and with a T-score $>60$ as almost certainly depressed. The internal consistency of the BDIII for baseline scores in the current sample was excellent $(\alpha=0.96)$.

Beck Hopelessness Scale (BHS; Beck et al., 1974), French validation by Bouvard et al. (1992), is a 20 -item true/false scale that assesses key aspects of hopelessness: (a) negative feelings about the future, (b) loss of motivation and (c) lack of hope. Higher scores indicate a greater pessimism and an increased risk of suicide. The BHS has rarely been used to assess hopelessness in autistic individuals (Cashin et al., 2013; Koegel et al., 2016). However, it is the most frequently used instrument for the measurement of hopelessness in clinical and non-clinical populations. In both clinical and non-clinical samples, the measure has good psychometric properties (e.g. Beck et al., 1974; Bouvard et al., 1992; Steed, 2001; Kliem et al., 2018). In clinical populations, the BHS proved to discriminate between individuals with a high and moderate risk of suicide, as well as individuals with and without a history of suicide attempts (Granö et al., 2017; Balsamo et al., 2020). The internal consistency of the BHS for baseline scores in the current sample was $\operatorname{good}(\alpha=0.82)$. 
Eight-item General Alexithymia Factor Score (GAFS-8; Williams \& Gotham, 2021) is an 8-item unidimensional scale that measures alexithymia using eight items derived from the Toronto Alexithymia Scale (TAS-20; Bagby et al., 1994). The selection of items (TAS-20 items: 1, 2, 6, 9, 11, 12,13 , and 14) has been found to be a reliable measure of alexithymia in autistic adults (Williams \& Gotham, 2021). The GAFS-8 is the only alexithymia score to be thoroughly validated in the autistic population to date (Williams \& Gotham, 2021). As the measure is recent and has not yet been validated in French, we referred to the corresponding items in the French version of the TAS-20 (Loas et al., 1996). The internal consistency of the GAFS- 8 for baseline scores in the current sample was excellent $(\alpha=0.93)$.

\section{Abbreviated World Health Organization Quality of Life Ques-} tionnaire (WHOQoL-BREF; The WHOQoL Group, 1998), French validation by Baumann et al. (2010), is a 26-item scale assessing 4 domains of perceived quality of life: (a) physical health, (b) psychological health, (c) social relationships and (d) environment. Items are scored on a 5-point Likert scale. The scores are transformed on a scale from 0 to 100 to enable comparisons to be made between domains composed of unequal numbers of items. The WHOQoLBREF has good psychometric properties (Skevington et al., 2004). Silva et al. (2014) suggested a cut-off of 60 as being reflective of a satisfactory quality of life. In autistic individuals, the WHOQoL-BREF has good psychometric properties (McConachie et al., 2018). The internal consistency of the WHOQoL-BREF domains for baseline scores in the current sample was good $(\alpha=0.83$ for the "Physical health" domain, $\alpha=0.94$ for the "Psychological health" domain, $\alpha=0.74$ for the "Social relationships" domain and $\alpha=0.85$ for the "Environment" domain).

The frequency of self-harm and suicidal behaviors, as well as the intensity of suicidal ideation, were tracked on the DBT diary card in which participants recorded their emotions, urges and target behaviors daily (Linehan, 1993). At follow-up, we sent participants 6 questions investigating whether the improvements achieved during therapy in terms of self-harming behaviors and suicidal ideation were maintained (e.g. Q1. Since the end of psychotherapy and up to now, have you had self-harming behaviors? Q2. If so, how many times approximately have these behaviors occurred during this period?).

\section{Data Analysis}

Descriptive feasibility results were expressed in means $(M)$, standard deviations (SD), numbers and percentages. Thematic analysis was applied to the transcripts of semi-structured interviews following the guidelines suggested by Braun and Clarke (2006). This required reading and re-reading transcripts to become familiar with the data, coding the content manually and generating main themes. DB carried out the process under the supervision of LW.

Given that the small sample size $(n=7)$ does not allow us to assume the normality of the data distribution, we used the Wilcoxon signed-rank test (Wilcoxon, 1945), a non-parametric alternative to the one-sample $t$ test, to analyze the preliminary efficacy outcomes. We performed Wilcoxon signed-rank for pairwise comparisons to assess whether significant differences occurred between pre- and post-treatment, and between pre-treatment and follow-up mean scores for each scale. The significant level was set at $p<0.05$. Pairs Rank-Biserial correlation coefficients $(r)$ were calculated to assess the effect size, $r$ around 0.1 being considered as small effect size, around 0.2 as medium effect size and over 0.5 as large effect size.

We also calculated Reliable Change Indices (RCI; Jacobson \& Truax, 1991) for the DERS total score and subscales scores. RCI indicates whether a change that occurred over time in an individual score (e.g., between a patient's pre-intervention and post-intervention assessment) is significantly greater than a difference that could have occurred due to random measurement error alone. The calculation formula is:

$\mathrm{RCI}=\left(\mathrm{X}_{\text {post }}-\mathrm{X}_{\mathrm{pre}}\right) / \sqrt{2 \times S D \sqrt{\left((1-r)^{2}\right)}}$

where: $X_{\text {post }}=$ post-treatment individual score, $X_{\text {pre }}=$ pretreatment individual score, $\mathrm{SD}=$ Standard deviation of the clinical sample, and $r=$ test-rest reliability of the measure.

The stability of the DERS has not yet been tested in autistic samples, therefore we referred to the test-retest reliability of the French version (Dan-Glauser \& Scherer, 2013). We note that this test-retest value does not consider the minor modifications introduced in the calculation of DERS total score and subscale scores with autistic adults. The calculation of the RCIs is therefore approximate, nevertheless informative. A RCI below -1.96 is considered as a negative reliable change reflecting a significant improvement on the DERS individual total and subscale scores and a RCI above 1.96 is considered as a positive reliable change reflecting a worsening on the DERS individual total and subscale scores (Jacobson \& Truax, 1991).

In case of missing data, we considered the overall mean of the scale or the subscale (Kaushal, 2014).

Finally, regarding self-harming behaviors and suicidal ideation, the changes observed in DBT diary cards and self-reported changes at follow-up were reported descriptively. 


\section{Results}

\section{Feasibility and Acceptability}

\section{Attrition Rate}

2 (29\%) participants out of seven dropped out from therapy. One dropout was due to concerns related to the risk of contracting COVID-19 when the group sessions were resumed in June 2020 after 2 months of lockdown and the other was due to professional reasons. The seven participants completed all assessments and missing data were rare (less than $5 \%$ ). The participant without a follow-up measure is the one who joined the group mid-therapy and completed the therapy with a time lag.

\section{Attendance Rate}

The mean attendance rate of the seven participants was $98 \%$ (Range $=90-100 \% ; \mathrm{SD}=4 \%$ ). Specifically, for the five participants who completed the therapy, the rate was $96 \%$ and for the two participants who only participated in the first half of the therapy, the rate was $100 \%$ before dropout. These rates reflect high adherence to the therapy. The majority of patients (five out of seven) wished to resume the group sessions after the lockdown, in compliance with the hospital's health protocol.

\section{Satisfaction Level}

Participants, including the two who completed only half the therapy, reported high satisfaction with the therapy as the CSQ-8 mean score was 3.59 out of 4 (Range =3.13-4; $\mathrm{SD}=0.31$ ) (Fig. 1). They were most satisfied with the quality of the skills training sessions, which they all rated at a maximum score of 4 . Their intention to return to the care unit if needed and their likelihood to recommend the therapy to a friend also scored high, respectively 3.43 and 3.57 out of 4 .

\section{Participants' Subjective Experiences}

Five main themes emerged from the thematic analysis (Braun \& Clarke, 2006) of the transcripts (Table 4): (a) The environment of the group, described as "caring" and "reassuring", allowed them to "feel confident". Some mentioned that the activity to normalize anxiety in the first session helped them to feel more relaxed; (b) the group setting of the skills training was considered rewarding due to the diversity of profiles; this led them to "feel less alone with personal difficulties" and to "meet people like me". Some

Fig. 1 Mean scores of the CSQ-8 items

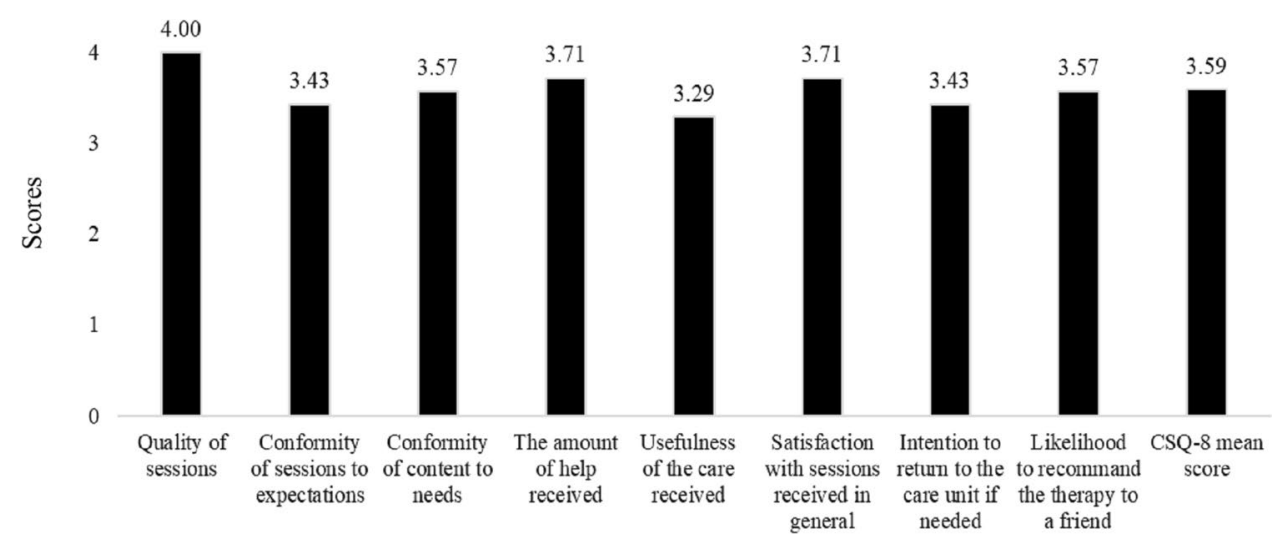

Table 4 Identified themes and example quotes

\begin{tabular}{|c|c|c|}
\hline & neme & Example quote \\
\hline 1 & The environment of the group skills training & It's a safe environment. I didn't identify any danger. I felt confident \\
\hline & The group setting of the skills training & $\begin{array}{l}\text { Being confronted with the group is difficult but necessary. We meet people like us and it has an } \\
\text { interesting resonance. You feel you belong to a group }\end{array}$ \\
\hline 3 & The content of the skills training group & $\begin{array}{l}\text { There are useful skills that I didn't have and that I discovered, especially understanding and } \\
\text { naming emotions, because it was difficult for me to identify what I was feeling }\end{array}$ \\
\hline & The individual therapy sessions & $\begin{array}{l}\text { The individual therapy sessions were very helpful. It allows you to dissect and better under- } \\
\text { stand situations and then put the skills together }\end{array}$ \\
\hline & The building of a life worth living & $\begin{array}{l}\text { I see other possibilities for the future than dying. I've screwed up many years, I've screwed up } \\
\text { my body, now I can do something else with my life }\end{array}$ \\
\hline
\end{tabular}


participants suggested that interactions between participants during group sessions could be further encouraged by the facilitators. Only one participant reported that he would have preferred to benefit from the skills training in an individual setting; (c) the skills learned were considered "useful", "diverse", "applicable" and "effective". Some participants suggested adding short and regular skills reviews during the group sessions; (d) the individual weekly therapy sessions were considered essential as they allowed participants to "dissect specific real-life situations", "put skills together", and "step back from emotional episodes"; and (e) DBT helped participants to start building a life worth living as they felt that they could "accept themselves and their ASD more", "survive crisis episodes", "allow themselves to have more fun activities", "identify one's values" and to take steps in valued directions. One participant reported having "a new and healthier life", which led her to grieve the life before therapy where suicide attempts and hospitalizations were frequent.

\section{Preliminary Efficacy}

Wilcoxon signed-rank test comparisons of the mean preand post-treatment scores revealed significant improvements with large effect sizes (Table 5). The mean DERS total score, assessing self-reported ED, decreased significantly post-treatment $(p=0.036, r=-1.00)$. This improvement was maintained at follow-up $(p=0.031, r=-1.00)$. In addition, 4 (57\%) of the seven participants had a follow-up score below the cut-off of 96 (Fig. 2).

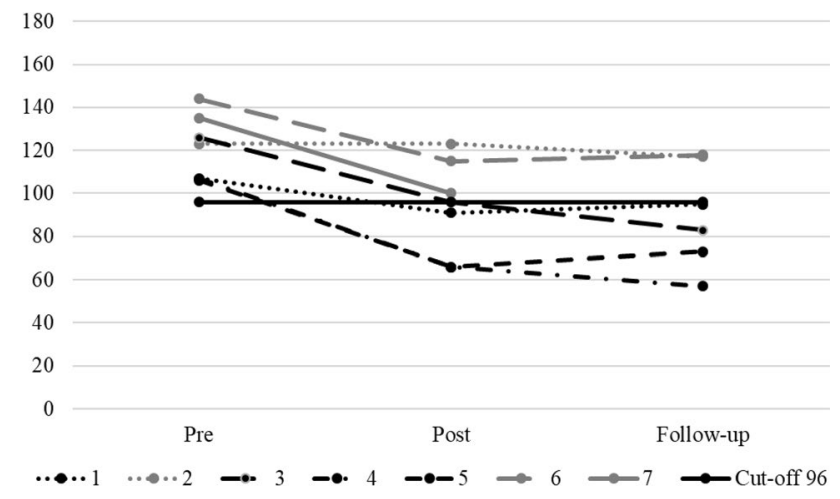

Fig. 2 Individual DERS total scores across the study

On the level of the DERS subscales, the mean scores of three subscales decreased significantly post-treatment with this decrease being maintained at follow-up: "Awareness" (post-treatment: $p=0.036, r=-1.00$; follow-up: $p=0.031$, $r=-1.00$ ), "Impulse" (post-treatment: $p=0.036, r=-1.00$; follow-up: $p=0.034, r=-1.00)$ and "Strategies" (post-treatment: $p=0.035, r=-1.00$; follow-up: $p=0.036, r=-1.00$ ).

At the intra-individual level, the DERS total scores showed a negative reliable change $(\mathrm{RCI}<-1.96)$, i.e., diminished self-reported ED, for 6 (86\%) participants out of seven post-treatment. Among the five participants that improved and had a follow-up assessment, the decrease in the DERS total score was maintained for $4(80 \%)$ of them (Table 6). On the subscale level, 5 (71\%) participants out of seven demonstrated reliable improvement at the "Strategies"

Table 5 Comparison of the preliminary efficacy outcomes by Wilcoxon signed-rank test

\begin{tabular}{|c|c|c|c|c|c|c|c|c|c|c|}
\hline & \multicolumn{2}{|l|}{ Pre } & \multicolumn{2}{|l|}{ Post } & \multicolumn{2}{|c|}{ Follow-up } & \multicolumn{2}{|l|}{ Pre-post } & \multicolumn{2}{|c|}{ Pre-followup } \\
\hline & Mean & SD & Mean & SD & Mean & SD & $p$ & Effect size & $p$ & Effect size \\
\hline DERS total & 121.14 & 15.12 & 93.86 & 21.98 & 90.50 & 24.35 & $0.036^{*}$ & -1.000 & $0.031 *$ & -1.000 \\
\hline Non-acceptance & 18.57 & 6.60 & 14.57 & 7.59 & 15.33 & 5.39 & 0.219 & -0.571 & 0.462 & -0.381 \\
\hline Awareness & 28.43 & 6.88 & 20.14 & 6.49 & 18.50 & 4.93 & $0.036^{*}$ & -1.000 & $0.031 *$ & -1.000 \\
\hline Goals & 21.14 & 2.12 & 20.00 & 2.52 & 19.33 & 4.84 & 0.134 & -0.800 & 0.293 & -0.524 \\
\hline Impulse & 21.71 & 6.42 & 15.71 & 7.27 & 13.33 & 5.39 & $0.036^{*}$ & -1.000 & $0.034 *$ & -1.000 \\
\hline Strategies & 23.00 & 5.51 & 17.57 & 3.55 & 16.50 & 5.24 & $0.035^{*}$ & -1.000 & $0.036^{*}$ & -1.000 \\
\hline Clarity & 8.29 & 2.29 & 5.86 & 3.24 & 7.50 & 3.83 & 0.062 & -0.821 & 1.000 & -0.048 \\
\hline BDI-II autism-specific ${ }^{\mathrm{T}-\text { score }}$ & 54.97 & 11.15 & 49.39 & 10.20 & 50.18 & 10.10 & $0.031^{*}$ & -0.929 & 0.313 & -0.524 \\
\hline BHS & 13.57 & 4.58 & 8.29 & 4.42 & 9.17 & 3.76 & $0.022 * *$ & -1.000 & 0.063 & -0.905 \\
\hline GAFS-8 & 26.00 & 10.31 & 23.29 & 7.78 & 20.29 & 6.45 & 0.293 & -0.524 & 0.293 & -0.524 \\
\hline \multicolumn{11}{|l|}{ WHOQoL-BREF } \\
\hline Physical health & 57.29 & 16.14 & 64.57 & 13.61 & 56.5 & 11.18 & 0.141 & 0.714 & 0.581 & -0.400 \\
\hline Psychological health & 32.14 & 24.94 & 42.86 & 22.66 & 38.67 & 20.86 & 0.181 & 1.000 & 0.684 & 0.267 \\
\hline Social relationships & 21.57 & 26.34 & 31.14 & 23.34 & 29.17 & 26.05 & 0.410 & 0.467 & 0.789 & 0.333 \\
\hline Environment & 72.43 & 13.23 & 80.71 & 15.38 & 73.00 & 14.04 & $0.035^{*}$ & 1.000 & 1.000 & 0.067 \\
\hline
\end{tabular}

${ }^{*} p<0.05$

${ }^{* * *} p<0.03$ 


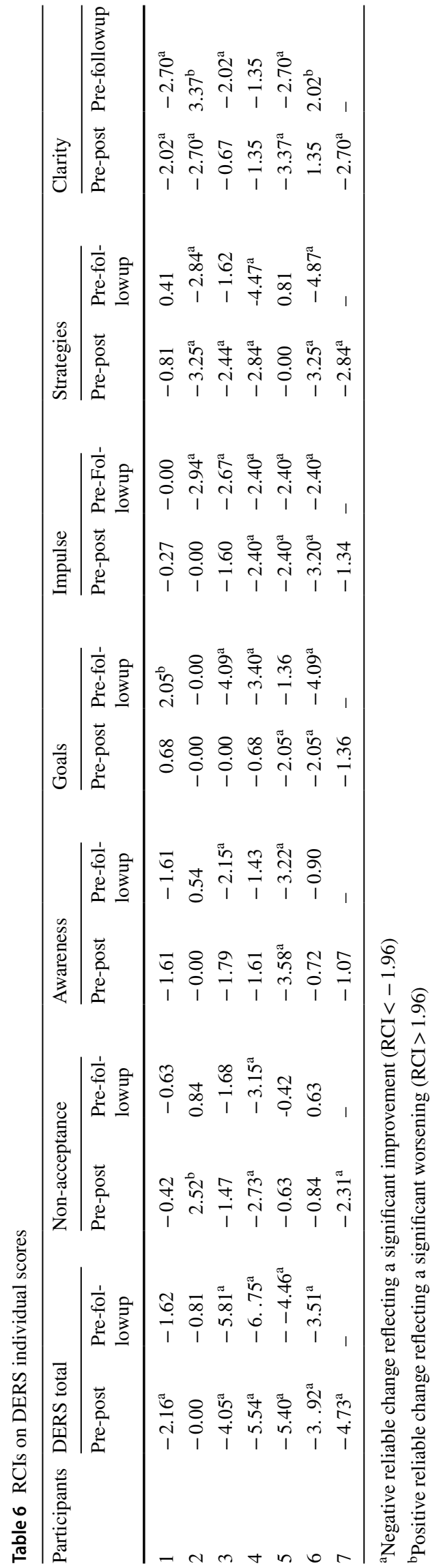

subscale post-treatment and $3(50 \%)$ out of 6 at follow-up. Reliable improvement was reported on the "Impulse" subscale by $3(43 \%)$ participants out of 7 post-treatment and by $5(83 \%)$ out of 6 at follow-up. On the "Awareness" subscale, one (14\%) participant out of 7 showed reliable improvement post-treatment and 2 (33\%) out of 6 at follow-up. On the "Clarity" subscale, reliable improvement was reported by 4 (57\%) participants out of seven post-treatment and by 3 (50\%) out of 6 at follow-up. 2 (30\%) participants showed a reliable worsening at follow-up on this scale, one of them after reliably improving post-treatment. On the "Goals" subscale, reliable improvement was reported by $2(28 \%)$ participants out of seven post-treatment and by $3(50 \%)$ out of 6 at follow-up. A reliable worsening was reported by one participant at follow-up at this subscale. Finally, on the "Nonacceptance" subscale, reliable improvement was reported by 2 (28\%) participants out of seven and reliable worsening by one participant (14\%) post-treatment. At follow-up, 1 (17\%) out of 6 showed a reliable improvement at this subscale.

Mean scores on the BDI-II and BHS also decreased significantly post-treatment (respectively, $p=0.031$ and $r=-0.93 ; p=0.022$ and $r=-1.00$ ) showing a decrease in self-reported levels of depression and hopelessness. Three participants had initial BDI-II autism-specific ${ }^{\mathrm{T}-\text { score }}$ on the severe range (1 almost certainly depressed and 2 very likely depressed), and they were on the moderate range post-treatment (Likely and possibly depressed); one participant's BDIII autism-specific ${ }^{\text {T-score }}$ changed from "possibly depressed" to "unlikely depressed" post-treatment. However, the significant improvements on the BDI-II and BHS mean scores were not maintained at follow-up (respectively, $p=0.313$ and $r=-0.52 ; p=0.063$ and $r=-0.90)$. The self-reported level of depression returned to baseline for 1 participant after improving post-treatment and worsened for another one at follow-up.

Regarding alexithymia, the decrease in the mean GAFS- 8 score was neither significant post-treatment $(p=0.293$, $r=-0.52)$ nor at follow-up ( $p=0.293, r=-0.52)$.

Concerning the perceived quality of life measured by the WHOQoL-BREF, only the mean score in the "Environment" domain increased significantly post-treatment $(p=0.035$, $r=1.00$ ), reflecting greater satisfaction with the living environment, leisure activities and access to care services. However, this significant improvement was not maintained at follow-up ( $p=1.00, r=-0.07)$.

All participants reported that DBT had a beneficial effect on their self-harm and/or suicidal behaviors, including suicidal ideation.

Of the four participants presenting with self-harm, 3 (80\%) reported on the DBT diary cards a complete cessation of self-harming behaviors for at least three months during therapy. At follow-up, 2 (50\%) participants reported that they had not engaged in self-harming behaviors during the 
4 months following the end of the therapy; and the other $2(50 \%)$ reported having had few self-harming behaviors (ranging from 2 to 4 ) during the 4-month follow-up period.

There were no suicide attempts during therapy and over the follow-up period. Participant seven (Table 2) who had been hospitalized several times the year prior to engaging in DBT was hospitalized neither during therapy nor during the 4-month follow-up period.

Of the 5 participants with suicidal ideation, $3(60 \%)$ reported that the decline in the frequency of suicidal thoughts observed during therapy continued over the 4-month follow-up period. One participant also reported a decrease in the intensity of suicidal ideation and a higher "tolerance threshold" towards situations that usually triggered suicidal thoughts post-treatment and at follow-up.

\section{Discussion}

Our study aimed to evaluate the feasibility, acceptability and preliminary efficacy of DBT in autistic adults without ID presenting with self-harm and/or suicidal behaviors. Our results suggest that DBT is feasible and might be efficacious in reducing ED in this context. These results are consistent with previous findings supporting the relevance of third-wave CBT approaches as a treatment of ED in autistic adults without ID (Conner \& White, 2018; Hartmann et al., 2019). Importantly, our results are the first to suggest that DBT might be feasible and clinically pertinent for autistic adults without ID presenting with self-harm and/or suicidal behaviors.

Firstly, our results reveal that DBT was feasible and highly acceptable to participants. Indeed, adherence to DBT was high and participants were highly satisfied with both group and individual sessions. Their subjective experience of DBT was overall positive, including group skills training, individual sessions, and the impact of DBT on building a life worth living. They also judged the adaptations introduced to DBT as relevant, consistent with findings suggesting that adaptations are required to foster the feasibility of psychotherapies in autistic individuals (Weston et al., 2016; Cooper et al., 2018). Moreover, it should be noted that in France, as in other European countries, psychological care for autistic adults is still underdeveloped, despite government efforts in recent years (Micai et al., 2021). This may have had an impact on the subjective feedback of the participants, as most of them were glad to have access to a psychological treatment conceived to address their specific needs.

Secondly, our results suggest that DBT might effectively reduce ED in autistic adults exhibiting self-harm and/or suicidal behaviors, as reflected by the significant decrease in the DERS total scores post-treatment and at follow-up. Specifically, the mean scores of the "Awareness", "Impulse" and "Strategies" subscales decreased significantly, with improvements being maintained at follow-up. In other clinical samples than autistic adults, previous findings suggest that DBT may have a significant positive effect on some (i.e., "Strategies" and "Goals") or all of the DERS subscales (e.g. Gibson et al., 2014; Neacsiu et al., 2014; Alavi et al., 2021). In our study, on the "Clarity" subscale, the mean score did not improve significantly, but on the intra-individual level, the RCIs of four participants showed a reliable improvement. These discrepant outcomes are due to the "Clarity" mean score which was impacted by the worsening of scores in two participants at follow-up; one of them was grieving the loss of a loved one at the time of the assessment. Regarding the "Goals" and "Non-acceptance" subscales, we hypothesize that skills related to these domains were less intensely addressed by the program than the skills related to "Awareness", "Impulse" and "Strategies". Indeed, "Nonacceptance" was mainly addressed in the session on "Radical acceptance" (one session of the distress tolerance module) and those related to "Goals" were targeted mainly in the session on "opposite action" (one session of the emotion regulation module). By contrast, "Awareness" was addressed during the three sessions of the mindfulness module and practiced at the beginning of each session; "Impulse", which refers to impulsivity during an emotional crisis, was taught during three sessions of the distress tolerance module; and "Strategies" encompasses the full range of DBT skills.

Regarding individual DERS total scores, the RCIs revealed a reliable improvement for six participants out of seven post-treatment, with four of them maintaining this improvement at follow-up. Individual scores improved the most on the "Impulse" and "Strategies" subscales. These improvements are consistent with those observed in the mean score level. However, the significant improvement in the mean score of the "Awareness" subscale was not reflected in the individual results, as only one participant out of seven showed a reliable improvement post-treatment and two out of six at follow-up. The test-retest reliability of this subscale is the lowest of the DERS subscales with $\rho=0.67$ (Dan-Glauser \& Scherer, 2013), which probably had an impact on the calculation of the RCIs of this subscale.

Overall, the significant improvement in self-reported ED is consistent with our clinical observations and with findings relative to DBT in several disorders (Panos et al., 2014; DeCou et al., 2019). It is also in line with the results of other studies targeting ED in autistic adults without cooccurring ID using third-wave CBT approaches, including interventions partially based on DBT (Conner \& White, 2018; Hartmann et al., 2019). However, our study is different from previous research due to: (a) the approach adopted, based entirely on DBT, and (b) the population of interest, i.e., autistic adults without ID exhibiting self-harm and/or suicidal behaviors associated with severe ED. The latter 
point is particularly important given that recent research has highlighted the high prevalence of self-harm and suicidal behaviors in this population and the lack of psychological interventions aiming to address them (Licence et al., 2019; Cassidy et al., 2020; Moseley et al., 2020).

The data collected on DBT diary cards showed that the majority of the participants with self-harm ceased these behaviors for at least 3 months up to the post-treatment measure, and this was maintained in half of them at follow-up. In only one participant, DERS total score did not improve, although self-harming behaviors did, with a complete cessation post-treatment and at follow-up. This discrepancy might be explained by contextual factors: The post-treatment and the follow-up assessments were conducted while this participant was experiencing work-related problems and grieving the loss of a family member. The frequency and severity of self-harm decreased in most of the participants. In addition, most of the participants reported a decline in the frequency of suicidal thoughts and no suicide attempt occurred during the study. These improvements are in line with previous studies that support the effectiveness of DBT in reducing suicidal behaviors (Panos et al., 2014; DeCou et al., 2019). Given the significant improvement in DERS mean scores, we hypothesize that the acquisition of emotion regulation skills enabled participants to cope more effectively with stressful situations. This is consistent with several findings suggesting that emotion regulation skills use is a key change mechanism of DBT (Lynch et al., 2006; Neacsiu et al., 2010; Mehlum, 2021).

Regarding self-reported depression, hopelessness and quality of life, significant improvements were achieved post-treatment but they were not sustained at follow-up. Post-treatment outcomes are consistent with previous studies showing that brief DBT formats result in a significant decrease in these clinical dimensions at the end of the treatment (Stanley et al., 2007; Mehlum et al., 2014; Swales et al., 2016; Sahranavard \& Miri, 2018). Other studies have found that changes in depression (e.g. Lynch et al., 2003; Neacsiu et al., 2014; Mehlum et al., 2019), hopelessness (e.g. Mehlum et al., 2019) and quality of life (Carter et al., 2010) measures were sustained at follow-up. In our sample, we hypothesize that the improvement observed on these dimensions was not sustained at follow-up due to the effects of the COVID-19 pandemic on the participants' mental health. Indeed, all of them reported increased depression and anxiety related to the pandemic, and one of them lost a family member due to COVID-19. Their reports are in line with findings showing that the COVID-19 pandemic increased the level of distress and depression in autistic individuals and decreased their quality of life (Mutluer et al., 2020; Patel et al., 2021). However, it is noteworthy that our main outcome, ED, proved resistant to the unfavorable context as the significant improvement in the DERS mean scores was maintained at follow-up.

Alexithymia is the only dimension that did not show statistically significant improvement following DBT neither post-treatment nor at follow-up. This result is inconsistent with the significant improvement in the mean score of the "Awareness" DERS subscale—referring to difficulties in recognizing one's emotions-observed in our sample. However, we note that alexithymia cannot be reduced to "Awareness", i.e., being aware of one's emotions. Indeed, it also encompasses difficulties in describing one's feelings, externally orientated thinking and constricted imaginal processes (Goerlich, 2018). Hence, it is possible that the participants became more aware of their emotions following DBT, but they still had difficulties in labeling them, as well as flexibly orienting their attention and their imagination processes. Attention and imagination peculiarities are core difficulties found in autistic individuals, which were only marginally targeted by our DBT intervention. Hence the lack of significant improvement on the GAFS-8 in our study might be explained by the fact that alexithymia was not the main target of our intervention (Cameron et al., 2014). Alexithymia has rarely been measured in DBT protocols (Bianchini et al., 2019; Holmqvist Larsson et al., 2020), and it is still unknown whether and how it changes in other clinical populations during the course of DBT.

Given that our study is the first to assess the feasibility, acceptability and clinical pertinence of DBT in autistic adults without ID, several limitations are to be noted. First, the sample size $(n=7)$ was small, which does not allow generalizing the results to the target population. Second, there was no control group, which does not allow providing definitive evidence that the improvements found here are due to DBT. Regarding these two limitations, larger sample sizes and the use of control groups are needed in future studies to investigate the efficacy of DBT in controlled trials with autistic adults without ID presenting with self-harm and/or suicidal behaviors. Third, the duration of participation was heterogeneous (two patients completed half of the therapy) due to the dropouts caused by the pandemic, which may have influenced outcomes. Fourth, the study sample was heterogeneous in terms of age, IQ, and severity of self-harm and suicidal behaviors, making it difficult to determine the clinical characteristics of the autistic adults that can benefit the most from the treatment. However, this heterogeneity might be considered as representative of the variability present among the autistic population (Masi et al., 2017). Our sample was homogeneous in terms of ethnicity, however, as all participants were white Europeans. To determine whether DBT is pertinent to the autistic population irrespective of ethnicity, future studies should consider including diverse samples with various ethnic and cultural backgrounds. 
Fifth, all the measures were self-reported. This can be particularly problematic since autistic individuals might present with high levels of alexithymia, which can interfere with their ability to recognize their emotional states (Kinnaird et al., 2019; Ziermans et al., 2019). However, all measures used here, except the BHS, have been proven to be reliable and valid in autistic adults (DERS: McVey et al., 2021; BDI-II: Williams et al., 2021; GAFS-8: Williams \& Gotham, 2021; and WHOQoL-BREF: McConachie et al., 2018); the DERS, in particular, has recently been shown to be valid and reliable in autistic individuals in clinical settings, and has been suggested as potentially useful in trials evaluating the effectiveness of psychological interventions, such as DBT, on ED (McVey et al., 2021). Nevertheless, to gain further insight on how DBT might reduce ED in autistic individuals, future studies may consider including objective assessments such as physiological measures to quantify changes in ED (e.g. Vasilev et al., 2009; Davies et al., 2015). Sixth, the interviews and the qualitative analysis were conducted by the therapists involved in the study, which might have interfered with the neutrality required in the process. Indeed, since this was a feasibility trial, we favored feasibility-e.g., reduction of participants' social anxiety-over the maximization of neutrality. In future mixed methods studies investigating the efficacy of DBT on autistic individuals, the interviews and data analysis should be conducted by researchers who are not directly involved in the therapy (Sutton \& Austin, 2015). Moreover, the use of double-code transcripts (Raskind et al., 2019) and specific computer softwares (Cope, 2014) are warranted. Finally, our study was disrupted by the COVID-19 pandemic, which was the case for clinical research in general (Padala et al., 2020; Sathian et al., 2020). Despite this, we found that self-reported ED improved significantly post-treatment and at follow-up, whereas other mental health measures (e.g., depression) improved post-treatment and this was lost at follow-up. These results highlight the specific and robust impact of DBT on self-reported ED, which proved resilient despite the highly stressful conditions related to the pandemic.

Overall, our results are the first to suggest that DBT is feasible and they provide preliminary evidence for its efficacy for the treatment of severe ED in autistic adults without ID exhibiting self-harm and suicidal behaviors. These results bear important clinical relevance, given the lack of evidencebased psychological treatments targeting the specific needs of a large number of autistic adults presenting with ED associated with self-harm and/or suicidal behaviors. Importantly, they support the need to further study the efficacy of DBT in autistic adults without ID through randomized controlled trials (Huntjens et al., 2020).
Author Contributions DB and LW developed the study aim and protocol. They set up the protocol and provided the DBT treatment. LW also provided DBT supervision to DB. RC and SW were actively involved in recruiting participants. DB conducted the statistical and qualitative analyses with the help of SW and LW. DB wrote the first draft with LW, RC and SW provided feedback. All authors read and approved the final manuscript.

Funding This study was funded by Fondation FondaMental Young Researchers Grant 2019-2020 (France) and Fonds de Dotation Neuroglia 2020-2023 (DB's PhD grant). Findings were collected and analysed during DB's master's degree and subsequent $\mathrm{PhD}$.

\section{Declarations}

Conflict of interest The authors declare that they have no conflict of interest.

Ethical Approval All procedures performed in studies involving human participants were in accordance with the ethical standards of the institutional and/or national research committee and with the 1964 Helsinki declaration and its later amendments or comparable ethical standards. This article does not contain any studies with animals performed by any of the authors. The current study is the preliminary step for a randomized controlled trial (RCT) being conducted as part of DB's PhD project that was approved by the regional ethics committee of the East of France (No. SI 21.01.21.41923).

Informed Consent Informed consent was obtained from all individual participants included in the study.

\section{References}

Alavi, N., Stephenson, C., \& Rivera, M. (2021). Effectiveness of delivering dialectical behavioral therapy techniques by email in patients with borderline personality disorder: Nonrandomized controlled trial. JMIR Mental Health, 8(4), e27308. https://doi. org/10.2196/27308

Anderson, S., \& Morris, J. (2006). Cognitive behaviour therapy for people with asperger syndrome. Behavioural and Cognitive Psychotherapy, 34(3), 293-303. https://doi.org/10.1017/S1352 465805002651

Attkisson, C. C., \& Zwick, R. (1982). The client satisfaction questionnaire. Psychometric properties and correlations with service utilization and psychotherapy outcome. Evaluation and program planning, 5(3), 233-237. https://doi.org/10.1016/0149-7189(82) 90074-x

Attwood, T. (2003). Cognitive behaviour therapy (CBT). In L. Holliday Willey (Ed.), Asperger Syndrome in Adolescence. London: Jessica Kingsley Publishers.

Bagby, R. M., Taylor, G. J., \& Parker, J. D. A. (1994). The twenty-item toronto alexithymia scale - II. Convergent, discriminant, and concurrent validity. Journal of Psychosomatic Research, 38, 33-40. https://doi.org/10.1016/0022-3999(94)90006-X

Balsamo, M., Carlucci, L., Innamorati, M., Lester, D., \& Pompili, M. (2020). Further insights into the beck hopelessness scale (BHS): Unidimensionality among psychiatric inpatients. Frontiers in Psychiatry, 11, 727. https://doi.org/10.3389/fpsyt.2020.00727

Baumann, C., Erpelding, M. L., Régat, S., Collin, J. F., \& Briançon, S. (2010). The WHOQOL-BREF questionnaire: French adult population norms for the physical health, psychological health and social relationship dimensions. Revue D'epidemiologie et 
de Sante Publique, 58(1), 33-39. https://doi.org/10.1016/j.respe. 2009.10.009

Beck, A. T., Epstein, N., Brown, G., \& Steer, R. A. (1988). An inventory for measuring clinical anxiety: Psychometric properties. Journal of Consulting and Clinical Psychology, 56(6), 893-897. https://doi.org/10.1037/0022-006X.56.6.893

Beck, A. T., Steer, R. A., \& Brown, G. K. (1996). Manual for beck depression inventory-II. Psychological Corporation.

Beck, A. T., Weissman, A., Lester, D., \& Trexler, L. (1974). The measurement of pessimism: The hopeless-ness scale. Journal of Consulting and Clinical Psychology, 42, 861-865. https://doi.org/ $10.1037 / \mathrm{h} 0037562$

Bianchini, V., Cofini, V., Curto, M., Lagrotteria, B., Manzi, A., Navari, S., Ortenzi, R., Paoletti, G., Pompili, E., Pompili, P. M., Silvestrini, C., \& Nicolò, G. (2019). Dialectical behaviour therapy (DBT) for forensic psychiatric patients: An Italian pilot study. Criminal Behaviour and Mental Health: CBMH, 29(2), 122-130. https://doi.org/10.1002/cbm.2102

Bishop-Fitzpatrick, L., Minshew, N. J., \& Eack, S. M. (2013). A systematic review of psychosocial interventions for adults with autism spectrum disorders. Journal of Autism and Developmental Disorders, 43(3), 687-694. https://doi.org/10.1007/ s10803-012-1615-8

Bohus, M., Dyer, A. S., Priebe, K., Krüger, A., Kleindienst, N., Schmahl, C., Niedtfeld, I., \& Steil, R. (2013). Dialectical behaviour therapy for post-traumatic stress disorder after childhood sexual abuse in patients with and without borderline personality disorder: A randomised controlled trial. Psychotherapy and Psychosomatics, 82, 221-233. https://doi.org/10.1159/000348451

Bourque, P., \& Beaudette, D. (1982). Étude psychometrique du questionnaire de dépression de Beck auprès d'un échantillon d'étudiants universitaires francophones [Psychometric study of the Beck Depression Inventory on a sample of French-speaking university students]. Canadian Journal of Behavioural Sciencel Revue Canadienne Des Sciences Du Comportement, 14(3), 211218. https://doi.org/10.1037/h0081254

Bouvard, M., Charles, S., Guérin, J., Aimard, G., \& Cottraux, J. (1992). Etude de l'échelle de désespoir de Beck (hopelessness scale). Validation et analyse factorielle [Study of Beck's hopelessness scale. Validation and factor analysis]. L'Encephale, 18(3), 237-240.

Brown, C. E., \& Dunn, W. (2002). Adolescent/adult sensory profile: User's manual. NCS Pearson Inc.

Braun, V., \& Clarke, V. (2006). Using thematic analysis in psychology. Qualitative Research in Psychology, 3(2), 77-101. https://doi. org/10.1191/1478088706qp063oa

Cameron, K., Ogrodniczuk, J., \& Hadjipavlou, G. (2014). Changes in alexithymia following psychological intervention: A review. Harvard Review of Psychiatry, 22(3), 162-178. https://doi.org/ 10.1097/HRP.0000000000000036

Camm-Crosbie, L., Bradley, L., Shaw, R., Baron-Cohen, S., \& Cassidy, S. (2019). "People like me don't get support": Autistic adults' experiences of support and treatment for mental health difficulties, self-injury and suicidality. Autism: The International Journal of Research and Practice, 23(6), 1431-1441. https://doi.org/ $10.1177 / 1362361318816053$

Carter, G. L., Willcox, C. H., Lewin, T. J., Conrad, A. M., \& Bendit, N. (2010). Hunter DBT project: Randomized controlled trial of dialectical behaviour therapy in women with borderline personality disorder. The Australian and New Zealand Journal of Psychiatry, 44(2), 162-173. https://doi.org/10.3109/00048670903393621

Cashin, A., Browne, G., Bradbury, J., \& Mulder, A. (2013). The effectiveness of narrative therapy with young people with autism. Journal of child and adolescent psychiatric nursing official publication of the Association of Child and Adolescent Psychiatric Nurses, Inc, 26(1), 32-41. https://doi.org/10.1111/ jcap. 12020
Cassidy, S., Bradley, L., Shaw, R., \& Baron-Cohen, S. (2018). Risk markers for suicidality in autistic adults. Molecular Autism, 9(42), 1-14. https://doi.org/10.1186/s13229-018-0226-4

Cassidy, S., Bradley, P., Robinson, J., Allison, C., McHugh, M., \& Baron-Cohen, S. (2014). Suicidal ideation and suicide plans or attempts in adults with Asperger's syndrome attending a specialist diagnostic clinic: A clinical cohort study. The Lancet Psychiatry, 1, 142-147. https://doi.org/10.1016/S2215-0366(14)70248-2

Cassidy, S. A., Robertson, A., Townsend, E., O'Connor, R. C., \& Rodgers, J. (2020). Advancing our understanding of self-harm, suicidal thoughts and behaviours in autism. Journal of Autism and Developmental Disorders, 50, 3445-3449. https://doi.org/ 10.1007/s10803-020-04643-9

Chen, E. Y., Matthews, L., Allen, C., Kuo, J. R., \& Linehan, M. M. (2008). Dialectical behavior therapy for clients with binge-eating disorder or bulimia nervosa and borderline personality disorder. The International Journal of Eating Disorders, 41(6), 505-512. https://doi.org/10.1002/eat.20522

Collins, M., Shattell, M., \& Thomas, S. P. (2005). Problematic interviewee behaviors in qualitative research. Western Journal of Nursing Research, 27(2), 188-209. https://doi.org/10.1177/ 0193945904268068

Conner, C. M., Golt, J., Righi, G., Shaffer, R., Siegel, M., \& Mazefsky, C. A. (2020). A comparative study of suicidality and its association with emotion regulation impairment in large asd and us census-matched samples. Journal of Autism and Developmental Disorders, 325(50), 1-16. https://doi.org/10.1007/ s10803-020-04370-1

Conner, C. M., \& White, S. W. (2018). Brief report: Feasibility and preliminary efficacy of individual mindfulness therapy for adults with autism spectrum disorder. Journal of Autism and Developmental Disorders, 48(1), 290-300. https://doi.org/10.1007/ s10803-017-3312-0

Conner, C. M., White, S. W., Beck, K. B., Golt, J., Smith, I. C., \& Mazefsky, C. A. (2019). Improving emotion regulation ability in autism: The emotional awareness and skills enhancement (EASE) program. Autism, 23(5), 1273-1287. https://doi.org/10. $1177 / 1362361318810709$

Cooper, K., Loades, M. E., \& Russell, A. (2018). Adapting psychological therapies for autism. Research in Autism Spectrum Disorders, 45, 43-50. https://doi.org/10.1016/j.rasd.2017.11.002

Cope, D. G. (2014). Computer-assisted qualitative data analysis software. Oncology Nursing Forum, 41(3), 322-323. https://doi.org/ 10.1188/14.ONF.322-323

Costa, A. P., Loor, C., \& Steffgen, G. (2020). Suicidality in adults with autism spectrum disorder: The role of depressive symptomatology, alexithymia, and antidepressants. Journal of Autism and Developmental Disorders, 50, 3585-3597. https://doi.org/10. 1007/s10803-020-04433-3

Dan-Glauser, E. S., \& Scherer, K. R. (2013). The difficulties in emotion regulation scale (DERS): Factor structure and consistency of a French translation. Swiss Journal of Psychology, 72(1), 5-11. https://doi.org/10.1024/1421-0185/a000093

Davies, C. D., Niles, A. N., Pittig, A., Arch, J. J., \& Craske, M. G. (2015). Physiological and behavioral indices of emotion dysregulation as predictors of outcome from cognitive behavioral therapy and acceptance and commitment therapy for anxiety. Journal of Behavior Therapy and Experimental Psychiatry, 46, 35-43. https://doi.org/10.1016/j.jbtep.2014.08.002

DeCou, C. R., Comtois, K. A., \& Landes, S. J. (2019). Dialectical behavior therapy is effective for the treatment of suicidal behavior: A meta-analysis. Behavior Therapy, 50, 60-72. https://doi. org/10.1016/j.beth.2018.03.009

Dell'Osso, L., Carpita, B., Muti, V. D., Morelli, V., Salarpi, G., Salerni, A., Scotto, J., Massimetti, G., Gesi, C., Ballerio, M., Signorelli, M. S., Luciano, M., Politi, P., Aguglia, E., Carmassi, C., \& Maj, 
M. (2019). Mood symptoms and suicidality across the autism spectrum. Comprehensive Psychiatry, 91, 34-38. https://doi.org/ 10.1016/j.comppsych.2019.03.004

Delparte, C. A., Power, H. A., Gelinas, B. L., Oliver, A. M., Hart, R. D., \& Wright, K. D. (2019). Examination of the effectiveness of a brief, adapted dialectical behavior therapy-skills training group for bariatric surgical candidates. Obesity Surgery, 29(1), 252-261. https://doi.org/10.1007/s11695-018-3515-2

Erford, B. T., Johnson, E., \& Bardhoshi, G. (2016). Meta-analysis of the English version of the beck depression inventory-second edition. Measurement and Evaluation in Counseling and Development, 49(1), 3-33. https://doi.org/10.1177/0748175615596783

Factor, R. S., Swain, D. M., Antezana, L., Muskett, A., Gatto, A. J., Radtke, S. R., \& Scarpa, A. (2019). Teaching emotion regulation to children with autism spectrum disorder: Outcomes of the Stress and Anger Management Program (STAMP). Bulletin of the Menninger Clinic, 83(3), 235-258. https://doi.org/10.1521/ bumc.2019.83.3.235

Fleming, A. P., McMahon, R. J., Moran, L. R., Peterson, A. P., \& Dreessen, A. (2015). Pilot randomized controlled trial of dialectical behavior therapy group skills training for ADHD among college students. Journal of Attention Disorders, 19, 260-271. https://doi.org/10.1177/1087054714535951

Gibson, J., Booth, R., Davenport, J., Keogh, K., \& Owens, T. (2014). Dialectical behaviour therapy-informed skills training for deliberate self-harm: A controlled trial with 3-month follow-up data. Behaviour Research and Therapy, 60, 8-14. https://doi.org/10. 1016/j.brat.2014.06.007

Goerlich, K. S. (2018). The multifaceted nature of alexithymia - A neuroscientific perspective. Frontiers in Psychology, 9, 1614. https://doi.org/10.3389/fpsyg.2018.01614

Granö, N., Oksanen, J., Kallionpää, S., \& Roine, M. (2017). Specificity and sensitivity of the Beck Hopelessness Scale for suicidal ideation among adolescents entering early intervention service. Nordic Journal of Psychiatry, 71(1), 72-76. https://doi.org/10. 1080/08039488.2016.1227370

Gratz, K. L., \& Roemer, L. (2004). Multidimensional assessment of emotion regulation and dysregulation: Development, factor structure, and initial validation of the difficulties in emotion regulation scale. Journal of Psychopathology and Behavioral Assessment, 26, 41-54. https://doi.org/10.1023/B:JOBA.0000007455.08539. 94

Gross, J. J. (1998). Antecedent- and response-focused emotion regulation: Divergent consequences for experience, expression, and physiology. Journal of Personality and Social Psychology, 74, 224-237. https://doi.org/10.1037/0022-3514.74.1.224

Grove, R., Roth, I., \& Hoekstra, R. A. (2016). The motivation for special interests in individuals with autism and controls: Development and validation of the special interest motivation scale. Autism Research: Official Journal of the International Society for Autism Research, 9(6), 677-688. https://doi.org/10.1002/aur. 1560

Haigh, S. M., Walsh, J. A., Mazefsky, C. A., Minshew, N. J., \& Eack, S. M. (2018). Processing speed is impaired in adults with autism spectrum disorder, and relates to social communication abilities. Journal of Autism and Developmental Disorders, 48(8), 26532662. https://doi.org/10.1007/s10803-018-3515-z

Harley, R. M., Sprich, S., Safren, S., Jacobo, M., \& Fava, M. (2008). Adaptation of dialectical behavior therapy skills training group for treatment-resistant depression. The Journal of Nervous and Mental Disease, 196(2), 136-143. https://doi.org/10.1097/NMD. 0b013e318162aa3f

Hartmann, K., Urbano, M., Manser, K. \& Okwara L. (2012). 'Modified Dialectical Behavior Therapy to Improve Emotion Regulation in Autism Spectrum Disorders.' Dans C.E Richardson et R. A.
Wood (eds) Autism Spectrum Desorders. Hauppauge, NY: Nova Science Publishers.

Hartmann, K., Urbano, M., Raffaele, C. T., Kreiser, N. L., Williams, T. V., Qualls, L. R., \& Elkins, D. E. (2019). Outcomes of an emotion regulation intervention group in young adults with autism spectrum disorder. Bulletin of the Menninger Clinic, 83(3), 259277. https://doi.org/10.1521/bumc.2019.83.3.259

Hedley, D., \& Uljarević, M. (2018). Systematic review of suicide in autism spectrum disorder: Current trends and implications. Current Disorders Reports, 5(1), 65-76. https://doi.org/10.1007/ s40474-018-0133-6

Hedley, D., Uljarević, M., Wilmot, M., Richdale, A., \& Dissanayake, C. (2017). Brief report: Social support, depression and suicidal ideation in adults with autism spectrum disorder. Journal of Autism and Developmental Disorders, 47(11), 3669-3677. https://doi. org/10.1007/s10803-017-3274-2

Hirvikoski, T., Mittendorfer-Rutz, E., Boman, M., Larsson, H., Lichtenstein, P., \& Bölte, S. (2016). Premature mortality in autism spectrum disorder. The British Journal of Psychiatry, 208(3), 232-238. https://doi.org/10.1192/bjp.bp.114.160192

Hirvikoski, T., Waaler, E., \& Alfredsson, J. (2011). Reduced ADHD symptoms in adults with ADHD after structured skills training group: Results from a randomized controlled trial. Behaviour Research and Therapy, 49, 175-185. https://doi.org/10.1016/j. brat.2011.01.001

Hollocks, M. J., Lerh, J. W., Magiati, I., Meiser-Stedman, R., \& Brugha, T. S. (2019). Anxiety and depression in adults with autism spectrum disorder: A systematic review and meta-analysis. Psychological Medicine, 49, 559-572. https://doi.org/10. 1017/S0033291718002283

Huntjens, A., van den Bosch, L. M. C. W., Sizoo, B., Kerkhof, A., Huibers, M. J. H., \& van der Gaag, M. (2020). The effect of dialectical behaviour therapy in autism spectrum patients with suicidality and/ or self-destructive behaviour (DIASS): Study protocol for a multicentre randomised controlled trial. BMC Psychiatry, 20, 127. https://doi.org/10.1186/s12888-020-02531-1

Hus, V., \& Lord, C. (2014). The autism diagnostic observation schedule, module 4: Revised algorithm and standardized severity scores. Journal of Autism and Developmental Disorders, 44(8), 1996-2012. https://doi.org/10.1007/s10803-014-2080-3

Jacobson, N. S., \& Truax, P. (1991). Clinical significance: A statistical approach to defining meaningful change in psychotherapy research. Journal of Consulting and Clinical Psychology, 59(1), 12-19. https://doi.org/10.1037/0022-006X.59.1.12

Kiep, M., Spek, A. A., \& Hoeben, L. (2015). Mindfulness-based therapy in adults with an autism spectrum disorder: Do treatment effects last? Mindfulness, 6(3), 637-644. https://doi.org/10.1007/ s12671-014-0299-x

Kinnaird, E., Stewart, C., \& Tchanturia, K. (2019). Investigating alexithymia in autism: A systematic review and meta-analysis. European Psychiatry, 55, 80-89. https://doi.org/10.1016/j.eurpsy. 2018.09.004

Kliem, S., Lohmann, A., Mößle, T., \& Brähler, E. (2018). Psychometric properties and measurement invariance of the Beck hopelessness scale (BHS): Results from a German representative population sample. BMC Psychiatry, 18(1), 110. https://doi.org/10.1186/ s12888-018-1646-6

Koegel, L. K., Navab, A., Ashbaugh, K., \& Koegel, R. L. (2016). Using reframing to reduce negative statements in social conversation for adults with autism spectrum disorder. Journal of Positive Behavior Interventions, 18(3), 133-144. https://doi.org/10.1177/ 1098300715596136

Kõlves, K., Fitzgerald, C., Nordentoft, M., Wood, S. J., \& Erlangsen, A. (2021). Assessment of suicidal behaviors among individuals with autism spectrum disorder in Denmark. JAMA Network 
Open, 4(1), e2033565. https://doi.org/10.1001/jamanetworkopen. 2020.33565

Koons, C. R., Robins, C. J., Tweed, J. L., Lynch, T. R., Gonzalez, A. M., Morse, J. Q., Bishop, G. K., Butterfield, M. I., \& Bastian, L. A. (2001). Efficacy of dialectical behavior therapy in women veterans with borderline personality disorder. Behavior Therapy, 32(2), 371-390. https://doi.org/10.1016/S0005-7894(01)80009-5

Kaushal, S. (2014). Missing data in clinical trials: Pitfalls and remedies. International Journal of Applied \& Basic Medical Research, 4(Suppl 1), S6-S7.

Holmqvist Larsson, K., Andersson, G., Stern, H., \& Zetterqvist, M. (2020). Emotion regulation group skills training for adolescents and parents: A pilot study of an add-on treatment in a clinical setting. Clinical Child Psychology and Psychiatry, 25(1), 141-155. https://doi.org/10.1177/1359104519869782

Linehan, M. M. (1993). Cognitive-behavioral treatment of borderline personality disorder. Guilford Press.

Licence, L., Oliver, C., Moss, J., \& Richards, C. (2019). Prevalence and risk-markers of self-harm in autistic children and adults. Journal of Autism and Developmental Disorders, 50(10), 3561-3574. https://doi.org/10.1007/s10803-019-04260-1

Linehan, M. M., Comtois, K. A., Murray, A. M., Brown, M. Z., Gallop, R. J., Heard, H. L., Korslund, K. E., Tutek, D. A., Reynolds, S. K., \& Lindenboim, N. (2006). Two-year randomized controlled trial and follow-up of dialectical behavior therapy vs therapy by experts for suicidal behaviors and borderline personality disorder. Archives of General Psychiatry, 63(7), 757-766. https://doi.org/ 10.1001/archpsyc.63.7.757

Linehan, M. M. (2017). Manuel d'entrainement aux compétences TCD (2ème éd., traduit par Prada P., Nicastro R., Perroud, N). Genève: Médecine et Hygiène.

Loas, G., Otmani, O., Verrier, A., Fremaux, D., \& Marchand, M. P. (1996). Factor analysis of the French version of the 20-item Toronto Alexithymia Scale (TAS-20). Psychopathology, 29(2), 139-144. https://doi.org/10.1159/000284983

Lord, C., Rutter, M., DiLavore, P. C., Risi, S., Gotham, K., \& Bishop, S. (2012). Autism diagnostic observation schedule-2. Los Angeles: Western Psychological Services.

Lynch, T. R., Chapman, A. L., Rosenthal, M. Z., Kuo, J. R., \& Linehan, M. M. (2006). Mechanisms of change in dialectical behavior therapy: Theoretical and empirical observations. Journal of Clinical Psychology, 62(4), 459-480. https://doi.org/10.1002/ jclp.20243

Lynch, T. R., Morse, J. Q., Mendelson, T., \& Robins, C. J. (2003). Dialectical behavior therapy for depressed older adults: A randomized pilot study. The American Journal of Geriatric Psychiatry, 11(1), 33-45. https://doi.org/10.1097/00019442-20030 1000-00006

Maddox, B. B., Crabbe, S. R., Fishman, J. M., Beidas, R. S., Brookman-Frazee, L., Miller, J. S., Nicolaidis, C., \& Mandell, D. S. (2019). Factors influencing the use of cognitive-behavioral therapy with autistic adults: A survey of community mental health clinicians. Journal of Autism and Developmental Disorders, 49(11), 4421-4428. https://doi.org/10.1007/s10803-019-04156-0

Maddox, B. B., Trubanova, A., \& White, S. W. (2017). Untended wounds: Non-suicidal self-injury in adults with autism spectrum disorder. Autism, 21(4), 412-422. https://doi.org/10.1177/13623 61316644731

Maddox, B. B., \& White, S. W. (2015). Comorbid social anxiety disorder in adults with autism spectrum disorder. Journal of Autism and Developmental Disorders, 45(12), 3949-3960. https://doi. org/10.1007/s10803-015-2531-5

Masi, A., DeMayo, M. M., Glozier, N., \& Guastella, A. J. (2017). An overview of autism spectrum disorder, heterogeneity and treatment options. Neuroscience Bulletin, 33(2), 183-193. https://doi. org/10.1007/s12264-017-0100-y
Mazefsky, C. A., Herrington, J., Siegel, M., Scarpa, A., Maddox, B. B., Scahill, L., \& White, S. W. (2013). The role of emotion regulation in autism spectrum disorder. Journal of the American Academy of Child and Adolescent Psychiatry, 52(7), 679-688. https://doi.org/10.1016/j.jaac.2013.05.006

Mazefsky, C. A., \& White, S. W. (2014). Emotion regulation: Concepts \& practice in autism spectrum disorder. Child and Adolescent Psychiatric Clinics of North America, 23(1), 15-24. https://doi.org/10.1016/j.chc.2013.07.002

McConachie, H., Mason, D., Parr, J. R., Garland, D., Wilson, C., \& Rodgers, J. (2018). Enhancing the validity of a quality of life measure for autistic people. Journal of Autism and Developmental Disorders, 48(5), 1596-1611. https://doi.org/10.1007/ s10803-017-3402-Z

McMain, S. F., Chapman, A. L., Kuo, J. R., Guimond, T., Streiner, D. L., Dixon-Gordon, K. L., Isaranuwatchai, W., \& Hoch, J. S. (2018). The effectiveness of 6 versus 12 -months of dialectical behaviour therapy for borderline personality disorder: The feasibility of a shorter treatment and evaluating responses (FASTER) trial protocol. BMC Psychiatry, 18(1), 230. https:// doi.org/10.1186/s12888-018-1802-z

McVey, A. J., Schiltz, H. K., Coffman, M., Antezana, L., \& Magnus, B. (2021). A preliminary psychometric analysis of the difficulties with emotion regulation scale (DERS) Among Autistic Adolescents and Adults: Factor Structure, Reliability, and Validity. Journal of autism and developmental disorders, https://doi.org/10.1007/s10803-021-05018-4. Advance online publication. https://doi.org/10.1007/s10803-021-05018-4

Mehlum, L. (2021). Mechanisms of change in dialectical behaviour therapy for people with borderline personality disorder. Current Opinion in Psychology, 37, 89-93. https://doi.org/10. 1016/j.copsyc.2020.08.017

Mehlum, L., Ramleth, R. K., Tørmoen, A. J., Haga, E., Diep, L. M., Stanley, B. H., Miller, A. L., Larsson, B., Sund, A. M., \& Grøholt, B. (2019). Long term effectiveness of dialectical behavior therapy versus enhanced usual care for adolescents with self-harming and suicidal behavior. Journal of Child Psychology and Psychiatry, and Allied Disciplines, 60(10), 1112-1122. https://doi.org/10.1111/jcpp.13077

Mehlum, L., Tørmoen, A. J., Ramberg, M., Haga, E., Diep, L. M., Laberg, S., Larsson, B. S., Stanley, B. H., Miller, A. L., Sund, A. M., \& Grøholt, B. (2014). Dialectical behavior therapy for adolescents with repeated suicidal and self-harming behavior: A randomized trial. Journal of the American Academy of Child and Adolescent Psychiatry, 53(10), 1082-1091. https://doi.org/ 10.1016/j.jaac.2014.07.003

Micai, M., Ciaramella, A., Salvitti, T., Fulceri, F., Fatta, L. M., Poustka, L., Diehm, R., Iskrov, G., Stefanov, R., Guillon, Q., Rogé, B., Staines, A., Sweeney, M. R., Boilson, A. M., Leósdóttir, T., Saemundsen, E., Moilanen, I., Ebeling, H., Yliherva, A., Gissler, M., Schendel, D. (2021). Intervention Services for Autistic Adults: An ASDEU Study of Autistic Adults, Carers, and Professionals' Experiences. Journal of autism and developmental disorders, https://doi.org/10.1007/s10803-02105038-0. Advance online publication. https://doi.org/10.1007/ s10803-021-05038-0

Morie, K. P., Jackson, S., Zhai, Z. W., Potenza, M. N., \& Dritschel, B. (2019). Mood disorders in high-functioning autism: The importance of alexithymia and emotional regulation. Journal of Autism and Developmental Disorders, 49(7), 2935-2945. https://doi.org/ 10.1007/s10803-019-04020-1

Moseley, R. L., Gregory, N. J., Smith, P., Allison, C., \& BaronCohen, S. (2019). A choice, an addiction, a way out of the lost: Exploring self-injury in autistic people without intellectual disability. Molecular Autism, 10, 18. https://doi.org/10.1186/ s13229-019-0267-3 
Moseley, R. L., Gregory, N. J., Smith, P., Allison, C., \& BaronCohen, S. (2020). Links between self-injury and suicidality in autism. Molecular Autism, 11, 1-15. https://doi.org/10.1186/ s13229-020-0319-8

Murphy, C. M., Wilson, C. E., Robertson, D. M., Ecker, C., Daly, E. M., Hammond, N., Galanopoulos, A., Dud, I., Murphy, D. G., \& McAlonan, G. M. (2016). Autism spectrum disorder in adults: Diagnosis, management, and health services development. Neuropsychiatric Disease and Treatment, 12, 1669-1686. https://doi. org/10.2147/NDT.S65455

Mutluer, T., Doenyas, C., \& Aslan Genc, H. (2020). Behavioral implications of the Covid-19 process for autism spectrum disorder, and individuals' comprehension of and reactions to the pandemic conditions. Frontiers in Psychiatry, 11, 561882. https://doi.org/ 10.3389/fpsyt.2020.561882

Neacsiu, A. D., Eberle, J. W., Kramer, R., Wiesmann, T., \& Linehan, M. M. (2014). Dialectical behavior therapy skills for transdiagnostic emotion dysregulation. A pilot randomized controlled trial Behaviour Research and Therapy, 59, 40-51. https://doi.org/10. 1016/j.brat.2014.05.005

Neacsiu, A. D., Rizvi, S. L., \& Linehan, M. M. (2010). Dialectical behavior therapy skills use as a mediator and outcome of treatment for borderline personality disorder. Behaviour Research and Therapy, 48(9), 832-839. https://doi.org/10.1016/j.brat. 2010.05.01

Nyrenius, J., \& Billstedt, E. (2020). The functional impact of cognition in adults with autism spectrum disorders. Nordic Journal of Psychiatry, 74(3), 220-225. https://doi.org/10.1080/08039488. 2019.1694698

Padala, P. R., Jendro, A. M., \& Padala, K. P. (2020). Conducting clinical research during the COVID-19 pandemic: Investigator and participant perspectives. JMIR Public Health and Surveillance. https://doi.org/10.2196/18887

Panos, P. T., Jackson, J. W., Hasan, O., \& Panos, A. (2014). Metaanalysis and systematic review assessing the efficacy of Dialectical behavior therapy (DBT). Research on Social Work Practice, 24(2), 213-223. https://doi.org/10.1177/1049731513503047

Pasieczny, N., \& Connor, J. (2011). The effectiveness of dialectical behaviour therapy in routine public mental health settings: An Australian controlled trial. Behaviour Research and Therapy, 49(1), 4-10. https://doi.org/10.1016/j.brat.2010.09.006

Patel, J. A., Badiani, A. A., Nielsen, F. B. H., Assi, S., Unadkat, V., Patel, B., Courtney, K., \& Hallas, L. (2021). COVID-19 and autism: Uncertainty, distress and feeling forgotten. Public Health in Practice, 1(3), 100034. https://doi.org/10.1016/j.puhip.2020. 100034

Philipsen, A., Graf, E., Jans, T., Matthies, S., Borel, P., Colla, M., et al. (2014). A randomized controlled multicenter trial on the multimodal treatment of adult attention-deficit hyperactivity disorder: Enrollment and characteristics of the study sample. $A D H D$ Attention Deficit and Hyperactivity Disorders, 6, 35-47. https:// doi.org/10.1007/s12402-013-0120-z

Raskind, I. G., Shelton, R. C., Comeau, D. L., Cooper, H., Griffith, D. M., \& Kegler, M. C. (2019). A review of qualitative data analysis practices in health education and health behavior research. Health Education \& Behavior: THe Official Publication of the Society for Public Health Education, 46(1), 32-39. https://doi. org/10.1177/1090198118795019

Reyes, N. M., Pickard, K., \& Reaven, J. (2019). Emotion regulation: A treatment target for autism spectrum disorder. Bulletin of the Menninger Clinic, 83(3), 205-234. https://doi.org/10.1521/bumc. 2019.83.3.205

Richa, S., Fahed, M., Khoury, E., \& Mishara, B. (2014). Suicide in autism spectrum disorders. Archives of Suicide Research, 18(4), 327-339. https://doi.org/10.1080/13811118.2013.824834
Robertson, A. E., David, R., \& Simmons, R. (2015). The sensory experiences of adults with autism spectrum disorder: A qualitative analysis. Perception, 44(5), 569-586. https://doi.org/10.1068/ p7833

Rutter, M., Le Couteur, A., \& Lord, C. (2003). ADI-R. Autism Diagnostic Interview Revised. Manual. Los Angeles: Western Psychological Services. https://doi.org/10.1007/978-1-4419-1698-3_ 894

Sabourin, S., Pérusse, D., \& Gendreau, P. (1989). The psychometric qualities of the Canadian-French version of the Client Satisfaction Questionnaire for psychotherapeutic services (CSQ-8 and CSQ-18B). Canadian Journal of Behavioural Science, 21(2), 147-159. https://doi.org/10.1037/h0079853

Safer, D. L., Telch, C. F., \& Agras, W. S. (2001). Dialectical behavior therapy for bulimia nervosa. The American Journal of Psychiatry, 158(4), 632-634. https://doi.org/10.1176/appi.ajp.158.4.632

Sahranavard, S., \& Miri, M. R. (2018). A comparative study of the effectiveness of group-based cognitive behavioral therapy and dialectical behavioral therapy in reducing depressive symptoms in Iranian women substance abusers. Psicologia, Reflexao $e$ Critica : Revista Semestral Do Departamento De Psicologia Da UFRGS, 31(1), 15. https://doi.org/10.1186/s41155-018-0094-z

Sathian, B., Asim, M., Banerjee, I., Pizarro, A. B., Roy, B., van TeijlingenBorges do Nascimento, E. R. I. J., \& Alhamad, H. K. (2020), Impact of COVID-19 on clinical trials and clinical research: A systematic review. Nepal Journal of Epidemiology, 10(3), 878887. https://doi.org/10.3126/nje.v10i3.31622

Shaffer, R. C., Wink, L. K., Ruberg, J., Pittenger, A., Adams, R., Sorter, M., Manning, P., \& Erickson, C. A. (2019). Emotion regulation intensive outpatient programming: Development, feasibility, and acceptability. Journal of Autism and Developmental Disorders, 49(2), 495-508. https://doi.org/10.1007/s10803-018-3727-2

Shattuck, P. T., Garfield, T., Roux, A. M., Rast, J. E., Anderson, K., Hassrick, E. M., \& Kuo, A. (2020). Services for adults with autism spectrum disorder: A systems perspective. Current Psychiatry Reports, 22(3), 13. https://doi.org/10.1007/ s11920-020-1136-7

Silva, P. A. B., Soares, S. M., Santos, J. F. G., \& Silva, L. B. (2014). Cut-off point for WHOQOL-Bref as a measure of quality of life of older adults. Revista De Saúde Pública, 48(3), 390-397. https://doi.org/10.1590/S0034-8910.2014048004912

Skevington, S. M., Lotfy, M., O'Connell, K. A., \& WHOQOL Group. (2004). The World Health Organization's WHOQOL-BREF quality of life assessment: psychometric properties and results of the international field trial. A report from the WHOQOL group. Quality of Life Research: An International Journal of Quality of Life Aspects of Treatment, Care and Rehabilitation, 13(2), 299310. https://doi.org/10.1023/B:QURE.0000018486.91360.00

Spek, A. A., van Ham, N. C., \& Nyklíček, I. (2013). Mindfulnessbased therapy in adults with an autism spectrum disorder: A randomized controlled trial. Research in Developmental Disabilities, 34, 246-253. https://doi.org/10.1016/j.ridd.2012.08.009

Stanley, B., Brodsky, B., Nelson, J. D., \& Dulit, R. (2007). Brief dialectical behavior therapy (DBT-B) for suicidal behavior and nonsuicidal self-injury. Archives of Suicide Research: Official Journal of the International Academy for Suicide Research, 11(4), 337-341. https://doi.org/10.1080/13811110701542069

Steed, L. (2001). Further validity and reliability evidence for beck hopelessness scale scores in a nonclinical sample. Educational and Psychological Measurement, 61(2), 303-316. https://doi.org/ $10.1177 / 00131640121971121$

Steenfeldt-Kristensen, C., Jones, C. A., \& Richards, C. (2020). The prevalence of self-injurious behaviour in autism: A meta-analytic study. Journal of Autism and Developmental Disorders, 50(11), 3857-3873. https://doi.org/10.1007/s10803-020-04443-1 
Sutton, J., \& Austin, Z. (2015). Qualitative research: Data collection, analysis, and management. The Canadian Journal of Hospital Pharmacy, 68(3), 226-231. https://doi.org/10.4212/cjhp.v68i3. 1456

Swales, M., Hibbs, R. A., Bryning, L., \& Hastings, R. P. (2016). Health related quality of life for young people receiving dialectical behaviour therapy (DBT): A routine outcome-monitoring pilot. Springerplus, 5(1), 1137. https://doi.org/10.1186/ s40064-016-2826-9

The WHOQOL Group. (1998). Development of the World Health Organization WHOQOL-BREF quality of life assessment. Social Psychological Medicine, 28, 551-558. https://doi.org/10.1017/ S0033291798006667

Thomson, K., Burnham Riosa, P., \& Weiss, J. A. (2015). Brief report of preliminary outcomes of an emotion regulation intervention for children with autism spectrum disorder. Journal of Autism and Developmental Disorders, 45(11), 3487-3495. https://doi. org/10.1007/s10803-015-2446-1

Turton, H., Berry, B., Danquah, A., \& Pratt, D. (2021). The relationship between emotion dysregulation and suicide ideation and behaviour: A systematic review. Journal of Affective Disorders Reports, 5, 100136. https://doi.org/10.1016/j.jadr.2021.100136

Vasilev, C. A., Crowell, S. E., Beauchaine, T. P., Mead, H. K., \& Gatzke-Kopp, L. M. (2009). Correspondence between physiological and self-report measures of emotion dysregulation: A longitudinal investigation of youth with and without psychopathology. Journal of Child Psychology and Psychiatry, and Allied Disciplines, 50(11), 1357-1364. https://doi.org/10.1111/j.14697610.2009.02172.x

Wallace, G. L., Kenworthy, L., Pugliese, C. E., Popal, H. S., White, E. I., Brodsky, E., \& Martin, A. (2016). Real-world executive functions in adults with autism spectrum disorder: profiles of impairment and associations with adaptive functioning and comorbid anxiety and depression. Journal of Autism and Developmental Disorders, 46(3), 1071-1083. https://doi.org/10.1007/ s10803-015-2655-7

Wechsler, D. (2011). Wechsler abbreviated scale of intelligence, second edition (WASI-II) (2nd ed.). San Antonio, TX: NCS Pearson. https://doi.org/10.1177/0734282912467756

Weiner, L. (2019). Évaluation de la faisabilité et de l'efficacité d'un groupe de thérapie comportementale dialectique (TCD) transnosographique : Le groupe de régulation EMOtionnelle (GREMO). French Journal of Psychiatry, 1, 24-25. https://doi.org/10.1016/j. fjpsy.2019.10.208

Weiss, J. A., Thomson, K., Burnham Riosa, P., Albaum, C., Chan, V., Maughan, A., Tablon, P., \& Black, K. (2018). A randomized waitlist-controlled trial of cognitive behavior therapy to improve emotion regulation in children with autism. Journal of Child Psychology and Psychiatry, 59(11), 1180-1191. https://doi.org/ 10.1111/jcpp. 12915

Weston, L., Hodgekins, J., \& Langdon, P. E. (2016). Effectiveness of cognitive behavioural therapy for people who have autistic spectrum disorders: A systematic review and meta-analysis. Clinical Psychology Review, 49, 41-54. https://doi.org/10.1016/j.cpr. 2016.08.001

Wilcoxon, F. (1945). Individual comparisons by ranking methods. Biometrics, 1, 80-83.

Williams, Z. J., Everaert, J., \& Gotham, K. O. (2021). Measuring depression in autistic adults: psychometric validation of the beck depression inventory-II. Assessment, 28(3), 858-876. https://doi. org/10.1177/1073191120952889

Williams, Z. J., \& Gotham, K. O. (2021). RETRACTED ARTICLE: Improving the measurement of alexithymia in autistic adults: A psychometric investigation and refinement of the twenty-item Toronto Alexithymia Scale. Molecular Autism, 12, 20. https:// doi.org/10.1186/s13229-021-00427-9

Williams, D. L., Minshew, N. J., \& Goldstein, G. (2015). Further understanding of complex information processing in verbal adolescents and adults with autism spectrum disorders. Autism the International Journal of Research and Practice, 19(7), 859-867. https://doi.org/10.1177/1362361315586171

Wolff, J. C., Thompson, E., Thomas, S. A., Nesi, J., Bettis, A. H., Ransford, B., Scopelliti, K., Frazier, E. A., \& Liu, R. T. (2019). Emotion dysregulation and non-suicidal self-injury: A systematic review and meta-analysis. European Psychiatry: THe Journal of the Association of European Psychiatrists, 59, 25-36. https://doi. org/10.1016/j.eurpsy.2019.03.004

Zahid, S., \& Upthegrove, R. (2017). Suicidality in autistic spectrum disorders: A systematic review. Crisis: The Journal of Crisis Intervention and Suicide Prevention, 38(4), 237-246. https://doi. org/10.1027/0227-5910/a000458

Ziermans, T., de Bruijn, Y., Dijkhuis, R., Staal, W., \& Swaab, H. (2019). Impairments in cognitive empathy and alexithymia occur independently of executive functioning in college students with autism. Autism, 23(6), 1519-1530. https://doi.org/10.1177/13623 61318817716

Publisher's Note Springer Nature remains neutral with regard to jurisdictional claims in published maps and institutional affiliations. 